\title{
A review of biomass burning emissions part III: intensive optical properties of biomass burning particles
}

\author{
J. S. Reid ${ }^{1}$, T. F. Eck ${ }^{2}$, S. A. Christopher ${ }^{3}$, R. Koppmann ${ }^{4}$, O. Dubovik ${ }^{3}$, D. P. Eleuterio ${ }^{5}$, B. N. Holben ${ }^{6}$, E. A. Reid ${ }^{1}$, \\ and J. Zhang ${ }^{3}$ \\ ${ }^{1}$ Marine Meteorology Division, Naval Research Laboratory, Monterey CA, USA \\ ${ }^{2}$ GEST Center, University of Maryland, Baltimore County, MD, USA \\ ${ }^{3}$ Dept. of Atmospheric Sciences, University of Alabama, Huntsville, AL, USA \\ ${ }^{4}$ Institut fuer Chemie und Dynamik der Geosphaere: Institut II: Troposphaere, Forschungszentrum Juelich, Germany \\ ${ }^{5}$ Dept. of Meteorology, Naval Postgraduate School, Monterey CA, USA \\ ${ }^{6}$ NASA Goddard Space Flight Center, Greenbelt MD, USA
}

Received: 19 April 2004 - Published in Atmos. Chem. Phys. Discuss.: 8 September 2004

Revised: 24 February 2005 - Accepted: 1 March 2005 - Published: 14 March 2005

\begin{abstract}
Because of its wide coverage over much of the globe, biomass burning has been widely studied in the context of direct radiative forcing. Such study is warranted as smoke particles scatter and at times absorb solar radiation efficiently. Further, as much of what is known about smoke transport and impacts is based on remote sensing measurements, the optical properties of smoke particles have far reaching effects into numerous aspects of biomass burning studies. Global estimates of direct forcing have been widely varying, ranging from near zero to $-1 \mathrm{~W} \mathrm{~m}^{-2}$. A significant part of this difference can be traced to varying assumptions on the optical properties of smoke. This manuscript is the third part of four examining biomass-burning emissions. Here we review and discuss the literature concerning measurement and modeling of optical properties of biomassburning particles. These include available data from published sensitivity studies, field campaigns, and inversions from the Aerosol Robotic Network (AERONET) of Sun photometer sites. As a whole, optical properties reported in the literature are varied, reflecting both the dynamic nature of fires, variations in smoke aging processes and differences in measurement technique. We find that forward modeling or "internal closure" studies ultimately are of little help in resolving outstanding measurement issues due to the high degree of degeneracy in solutions when using "reasonable" input parameters. This is particularly notable with respect to index of refraction and the treatment of black carbon. Consequently, previous claims of column closure may in fact be more ambiguous. Differences between in situ and retrieved $\omega_{o}$ values have implications for estimates of mass scattering and mass absorption efficiencies. In this manuscript we
\end{abstract}

Correspondence to: J. S. Reid

(reidj@nrlmry.navy.mil) review and discuss this community dataset. Strengths and lapses are pointed out, future research topics are prioritized, and best estimates and uncertainties of key smoke particle parameters are provided.

\section{Introduction}

Before the effects of smoke particles on the earth's radiative balance can be known, their optical properties need to be efficiently parameterized. Further, these parameterizations need to be physically consistent with the particle's other physical and emissions properties, which can vary significantly from region to region. Fundamental input parameters such as index of refraction and black carbon content are highly uncertain. Because smoke particles size range is in the steepest part of the scattering versus physical cross section curve, even small changes in estimated physical parameters can have significant impacts on scattering and absorption efficiencies. The result is a considerable amount of degeneracy in "closure" calculations and relatively easy justification for any experimental or modeling finding based on "physically sound" assumptions or parameterizations. This review paper is concerned specifically with these issues.

This review paper is the third of four examining biomassburning emissions and relies heavily on Part II (Reid et al., 2004), which deals with particle size and chemistry issues. Here we evaluate the radiative impacts of smoke particles along three principle lines: 1) Bulk parameterization from measurement, 2) direct forward calculation based on particle size distribution and chemistry, 3) the inverse problem where flux and radiance values are related to an optical equivalent size distribution. We begin with a review of field

(C) 2005 Author(s). This work is licensed under a Creative Commons License. 
Table 1. In situ measured optical properties of fresh smoke. WL=White light. Phase: F=Flaming, M=Mixed, S=Smoldering. $\alpha_{s}=$ mass scattering efficiency, $\alpha_{a}=$ mass absorption efficiency, $\omega_{o}=$ single scattering albedo, $\beta(1)=$ hem. backscatter fraction.

\begin{tabular}{|c|c|c|c|c|c|c|c|}
\hline Reference & \# Fires & $\lambda(\mathrm{nm})$ & Phase & $\alpha_{s}$ & $\alpha_{a}$ & $\omega_{o}$ & $\beta(1)$ \\
\hline \multicolumn{8}{|l|}{ Temporate and Boreal } \\
\hline Eccleson et al. (1974) & & 540 & $\mathrm{~F}$ & 4.2 & & & \\
\hline Hobbs et al. (1996) & 1 & 540 & $\mathrm{~F}$ & & & $0.85 \pm 0.03$ & \\
\hline Hobbs et al. (1996) & 4 & 550 & M & $3.8 \pm 0.2$ & $0.8 \pm 0.4$ & $0.90 \pm 0.06$ & \\
\hline Hobbs et al. (1996) & 2 & 540 & S & & & $0.97 \pm 0.02$ & \\
\hline Martins et al. (1996) & 4 & WL & $\mathrm{F}$ & & $1.2 \pm 0.2$ & & \\
\hline Martins et al. (1996) & 4 & WL & M & & $0.9 \pm 0.2$ & & \\
\hline Martins et al. (1996) & 1 & WL & $S$ & & $0.2 \pm 0.5$ & & \\
\hline Miller and O’Neill (1997) & 1 & 550 & $\mathrm{~F}$ & & & 0.7 & \\
\hline Miller and O'Neill (1997) & 1 & 672 & $\mathrm{~F}$ & & & 0.6 & \\
\hline Nance et al. (1993) & 3 & 540 & $\mathrm{~F}$ & $4.1 \pm 0.1$ & & & \\
\hline Radke et al. (1991) & 17 & 540 & M & 3.2 & $0.7 \pm 0.4$ & $0.83 \pm 0.11$ & \\
\hline Radke et al. (1988) & 7 & 550 & M & 3.9 & $0.7 \pm 0.4$ & $0.86 \pm 0.11$ & \\
\hline Tangren (1982) & & 550 & $\mathrm{~F}$ & 3.6 & & & \\
\hline \multicolumn{8}{|l|}{ Tropical Forest } \\
\hline Martins et al. (1998)* & 7 & WL & $\mathrm{F}$ & & $1.0 \pm 0.3$ & & \\
\hline Martins et al. (1998)* & 2 & WL & $\mathrm{S}$ & & $0.6 \pm 0.2$ & & \\
\hline Reid and Hobbs (1998) & 6 & 450 & $\mathrm{~F}$ & $4.5 \pm 0.4$ & & & $0.16 \pm 0.02$ \\
\hline Reid and Hobbs (1998) & 6 & 550 & $\mathrm{~F}$ & $2.8 \pm 0.5$ & $1.0 \pm 0.2$ & $0.74 \pm 0.06$ & $0.20 \pm 0.01$ \\
\hline Reid and Hobbs (1998) & 6 & 700 & $\mathrm{~F}$ & $1.6 \pm 0.3$ & & & $0.23 \pm 0.02$ \\
\hline Reid and Hobbs (1998) & 6 & 450 & $\mathrm{~S}$ & $5.5 \pm 0.5$ & & & $0.15 \pm 0.01$ \\
\hline Reid and Hobbs (1998) & 6 & 550 & $\mathrm{~S}$ & $3.6 \pm 0.4$ & $0.7 \pm 0.1$ & $0.84 \pm 0.02$ & $0.16 \pm 0.01$ \\
\hline Reid and Hobbs (1998) & 6 & 700 & $\mathrm{~S}$ & $1.9 \pm 0.3$ & & & $0.19 \pm 0.01$ \\
\hline Yamasoe et al. (2000) & 19 & WL & $\mathrm{F}$ & & $1.1 \pm 0.8$ & & \\
\hline Yamasoe et al. (2000) & 42 & WL & $\mathrm{S}$ & & $0.6 \pm 0.2$ & & \\
\hline \multicolumn{8}{|l|}{ Scrub Forest/Cerrado } \\
\hline Martins et al. (1998) & 8 & & $\mathrm{~F}$ & & $0.8 \pm 0.4$ & & \\
\hline Reid and Hobbs (1998) & 6 & 450 & $\mathrm{~F}$ & $5.1 \pm 0.5$ & & & $0.19 \pm 0.01$ \\
\hline Reid and Hobbs (1998) & 6 & 550 & $\mathrm{~F}$ & $3.4 \pm 0.6$ & $1.0 \pm 0.1$ & $0.77 \pm 0.03$ & $0.21 \pm 0.01$ \\
\hline Reid and Hobbs (1998) & 6 & 700 & $\mathrm{~F}$ & $1.8 \pm 0.3$ & & & $0.23 \pm 0.01$ \\
\hline Yamasoe et al. (2000) & 55 & WL & $\mathrm{F}$ & & $1.65 \pm 1$ & & \\
\hline Yamasoe et al. (2000) & 33 & WL & $\mathrm{S}$ & & $0.9 \pm 1$ & & \\
\hline \multicolumn{8}{|l|}{ Grasslands/Savanna } \\
\hline Abel et al. (2003) & 1 & 559 & $\mathrm{~F}$ & & & 0.84 & \\
\hline Evans et al. (1976) & 1 & 550 & $\mathrm{~F}$ & 3.1 & & & \\
\hline Reid and Hobbs (1998) & 6 & 450 & $\mathrm{~F}$ & $4.6 \pm 0.6$ & & & $0.15 \pm 0.02$ \\
\hline Reid and Hobbs (1998) & 6 & 550 & $\mathrm{~F}$ & $3.5 \pm 0.5$ & $1.1 \pm 0.2$ & $0.76 \pm 0.08$ & $0.17 \pm 0.02$ \\
\hline Reid and Hobbs (1998) & 6 & 700 & $\mathrm{~F}$ & $1.9 \pm 0.3$ & & & $0.19 \pm 0.02$ \\
\hline Vines (1971) & 1 & 500 & $\mathrm{~F}$ & 4.0 & & & \\
\hline \multicolumn{8}{|l|}{ Laboratory } \\
\hline Patterson et al. $(1984,1985)$ & & 550 & & $3.0-3.7$ & $0.7-1.1$ & $0.74 \pm 0.06$ & \\
\hline
\end{tabular}

* Inferred from black carbon and black carbon absorption efficiency measurements.

measurements of key optical parameters. We then compare these findings with forward modeled studies and column closure experiments. These are subsequently compared to solutions from inversion methods. In all of these sections we explore differences in particle properties by region and fire chemistry, and attempt to reconcile differences that exist be- tween investigation techniques. In conclusion we discuss our findings and present what we feel are reasonable parameters with likely uncertainties for smoke properties. Suggestions are made for future research. 


\section{Field measurements and bulk empirical parameteri- sations}

Bulk empirical modeling is often used for first order evaluations of the perturbation of the clear sky radiative balance by aerosol particles. Examples of the application of the bulk method to global radiative flux include Charlson et al. (1991) and Chylek and Wong (1995) for anthropogenic sulfates and Penner et al. (1992), and Hobbs et al. (1997) for biomass burning smoke. In these cases the bulk parameters are applied to a linear model that assumes an optically thin aerosol layer:

$\Delta \alpha_{p}=$

$\left[\mathrm{T}_{a}^{2}\left(1-\mathrm{A}_{c}\right)\right]\left[2\left(\left(1-\mathrm{R}_{s}\right)^{2} \bar{\beta} \alpha_{s} f(\mathrm{rh})-4 \mathrm{R}_{s} \alpha_{a}\right] \cdot \mathrm{M}_{c p}\right.$

Here $\Delta \alpha_{p}$ is the perturbation in planetary albedo due the particular aerosol species. The first term of this expression includes the atmospheric molecular transmittance, $\mathrm{T}_{a}$ (squared as the path rays go through the atmosphere twice: down and back up), and the cloud free fraction of the atmosphere susceptible to direct forcing, where $\mathrm{A}_{c}$ is the average cloud fraction (typically assumed to be $\sim 63 \%$ ).

To model direct radiative forcing due to aerosols under clear sky conditions using this bulk method, two extensive and four intensive parameters are needed. The extensive properties are surface albedo, $\mathrm{R}_{s}$ (included in term 2) and the average column integrated mass loading of the aerosol species of interest, $\mathbf{M}_{c p}$ (term 3). The four bulk aerosol optical properties that are needed in term 2 are:

1) Mass scattering efficiency $\alpha_{s}$ : The total light scattering cross section of $1 \mathrm{~g}$ of dry aerosol particles. The product of $\alpha_{s}$ and $\mathbf{M}_{c p}$ would give the total aerosol optical depth due to scattering in a dry atmosphere.

2) Hygroscopic growth factor $f(r h)$ : The amount that aerosol particle light scattering increases at high relative humidity due to the uptake of water. The product of $f(\mathrm{rh})$ with $\alpha_{s}$ and $\mathrm{M}_{c p}$ would give the total aerosol optical depth due to scattering in an ambient atmosphere (Note there is no hygroscopicity term for the absorption coefficient as it is close to 1 for all unsaturated conditions and consequently commonly neglected for smoke. This is not necessarily the case for more hygrososcopic species like most anthropogenics - Redeman et al., 2001).

3) Up-scatter fraction $\bar{\beta}$ : The total fraction of scattered light back to space by aerosol particles averaged over the course of a day. The up-scatter fraction, $\bar{\beta}$ is often parameterized through the particle asymmetry parameter, $\mathrm{g}$.

4) Particle absorption efficiency $\alpha_{a}$ : The total light absorption cross-section of $1 \mathrm{~g}$ of aerosol particles. Similarly, the product of $\alpha_{a}$ and $\mathrm{M}_{c p}$ would give the total aerosol optical depth due to absorption in a dry atmosphere.

There are many reasons why the linear method is inadequate when applied to biomass-burning aerosols. Most important is that particle concentrations in the hazes are typi- cally high, and hence the "optically thin" approximation does not hold. In both the optically thick and the inhomogeneous aerosol layer cases, Eq. (1). is inadequate, and more sophisticated models are needed. These more sophisticated models parameterize two of the intensive properties differently. First, instead of requiring mass absorption efficiency, the models require particle single scattering albedo, $\omega_{o}$, defined as the ratio of particle scattering to particle extinction (the sum of scattering and absorption coefficients):

$\omega_{o} \equiv \frac{\sigma_{s}}{\sigma_{e}}=\frac{\sigma_{s}}{\sigma_{s}+\sigma_{a}}=\frac{\alpha_{s}}{\alpha_{s}+\alpha_{a}}$

Second, the up-scatter fraction, $\bar{\beta}$ is replaced by the particle asymmetry parameter, g, which is discussed below.

\subsection{Mass scattering efficiency and Ångstrom Exponent}

The scattering of light by airborne particles is most often parameterized through the mass scattering efficiency, $\alpha_{s}\left(\mathrm{~m}^{2}\right.$ $\mathrm{g}^{-1}$ ), which is defined as:

$\sigma s=\alpha_{s} \cdot \mathrm{c}_{m} \cdot f(\mathrm{RH})$

where $\sigma_{s}$ is the particle light-scattering coefficient $\left(\mathrm{m}^{-1}\right), \mathrm{c}_{m}$ the particle concentration $\left(\mathrm{g} \mathrm{m}^{-3}\right)$, and $f(\mathrm{RH})$ the dimensionless hygroscopic growth factor. Hence, $\alpha_{s}$ has units of $\mathrm{m}^{2} \mathrm{~g}^{-1}$. The light scattering coefficient is typically measured with a nephelometer, and the mass concentration with an adjoining filter.

For fine-mode species such as sulfates, it has long been known that the bulk dry mass-scattering efficiency in midvisible wavelengths is on the order of 3 to $4 \mathrm{~m}^{2} \mathrm{~g}^{-1}$ (e.g., Waggoner et al., 1981). The spectrum of mass scattering measurements for fresh smoke is similar to sulfates, as seen in Table 1. Taken as a whole, there are very few fundamental measurements of this kind in the peer-reviewed literature (12 manuscripts total). Values of $\alpha_{s}$ have been derived for North and South America, as well as for some Australian biomes. However, to date there have not been reported measurements from Africa and Southeast Asia (although $\alpha_{s}$ has been inferred through forward calculations - see Sect. 3). Typical values of $\alpha_{s}$ for fresh smoke have mid-visible values ranging from 2.8 to $4.2 \mathrm{~m}^{2} \mathrm{~g}^{-1}$, and a mean value of roughly $3.6 \mathrm{~m}^{2} \mathrm{~g}^{-1}$, similar to the value suggested by IPCC (2001). The largest and most consistent data set can be inferred from the $\omega_{o}$ and $\alpha_{a}$ measurements from Radke et al. (1991), where 72 samples were taken from 13 temperate and boreal fires. In this study, the mean value of the mass scattering efficiency was $3.1 \mathrm{~m}^{2} \mathrm{~g}^{-1}$.

There are differences between data sets of in situ fresh smoke optical properties in Table 1 on the order of $30 \%$. For particle size distributions similar to smoke, larger volume median diameters imply larger mass scattering efficiency (on the order of $\sim 0.2 \mathrm{~m}^{2} \mathrm{~g}^{-1}$ per $0.01 \mu \mathrm{m}$ increase in VMD) and differences between reports are in part naturally correlated to the smoke particle's size, composition (e.g., black 

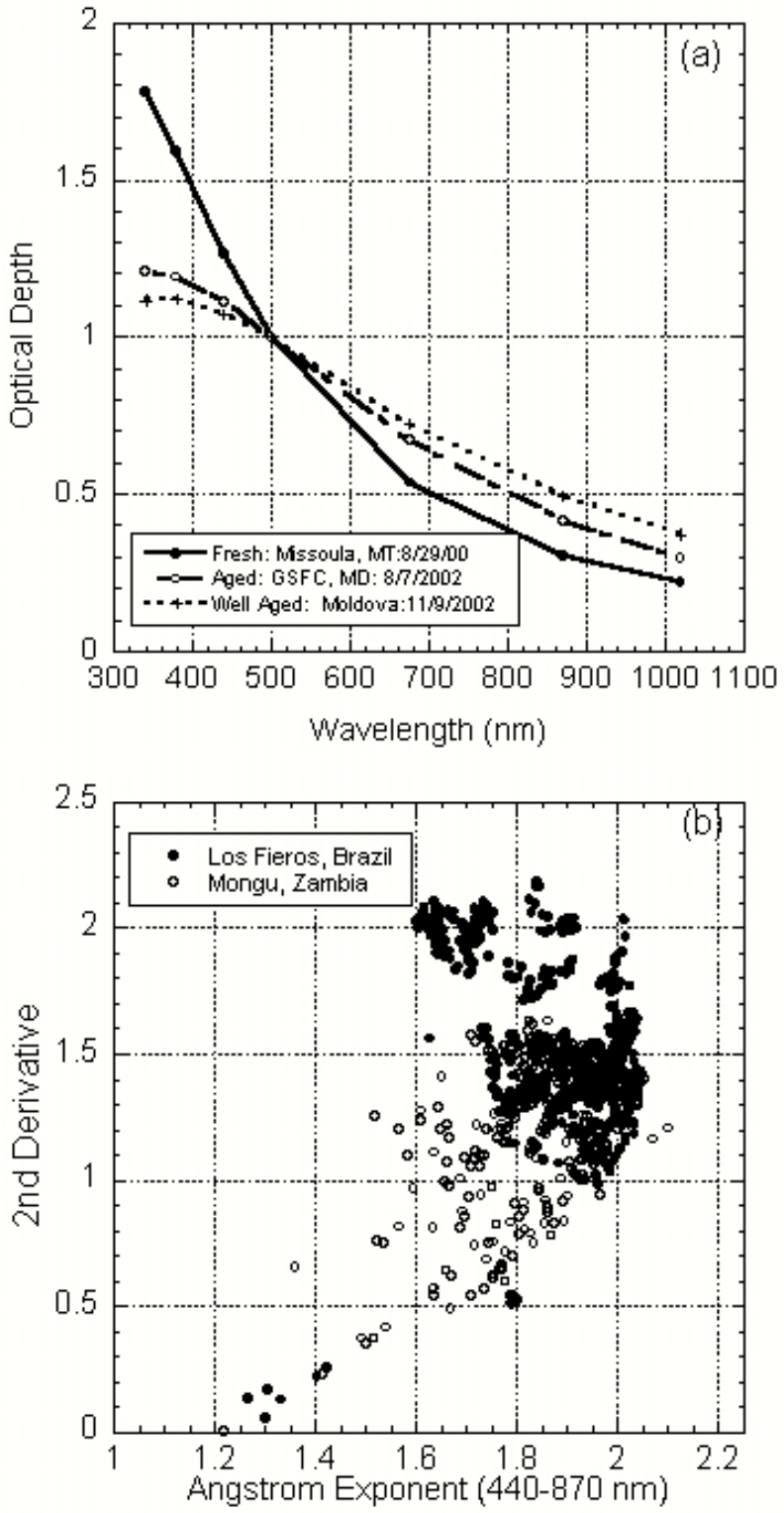

Fig. 1. (a) Wavelength dependence of optical depth for smoke only a few hours old in Montana, day old smoke from forest fires in Québec transported to Goddard Space Flight Center MD, and smoke aged for $\sim 2.5$ days in Moldova. Data was extracted from Eck et al. (2003). (b) Relationship between the Ångstrom exponent (Log derivative) and second derivative of the optical depthwavelength relationship for two sites in South America and Africa. Data was extracted from Eck et al. (1999, 2001).

carbon content), and density (e.g., see calculations by Reid and Hobbs, 1998). Consequently, particles from smoldering combustion with larger sizes and smaller black carbon contents have higher $\alpha_{s}$ values (increased by $\sim 25 \%$ ). However, due to differences in particle density, size increases alone do not necessarily manifest themselves as an increase in the $\alpha_{s}$ values of fresh smoke. For example, the mean $\alpha_{s}$ value of all forest fire data is $3.7 \mathrm{~m}^{2} \mathrm{~g}^{-1}$, compared to $3.5 \mathrm{~m}^{2} \mathrm{~g}^{-1}$ for grass or brush fires - hardly statistically significant. The data set of temperate and boreal forest fires, however, have some of the lowest reported values $\left(3.1 \mathrm{~m}^{2} \mathrm{~g}^{-1}\right)$ despite producing some of the largest sized particles (Reid et al., 2004). For tropical forests Reid and Hobbs (1998) found a larger variability with a $0.8 \mathrm{~m}^{2} \mathrm{~g}^{-1}$ difference between smoldering versus flaming combustion $\left(3.6 \mathrm{~m}^{2} \mathrm{~g}^{-1}\right.$ versus $2.8 \mathrm{~m}^{2} \mathrm{~g}^{-1}$ at $\lambda=550 \mathrm{~nm}$, respectively).

Particle $\alpha_{s}$ has a tendency to increase in aged smoke plumes due to the actions of particle growth through coagulation and condensation as well as through the enrichment of smoldering particles into continental scale plumes (see Part II of this series for a complete discussion of these mechanisms). Condensation can also decrease the geometric standard deviation of the particle distribution, which further increases $\alpha_{s}$ (see Sect. 3). To our knowledge, the only comparison of $\alpha_{s}$ for fresh and well-aged smoke ( +1 day) was performed by Reid et al. (1998b) for the smoky hazes over South America. There, they found a clear increase in $\alpha_{s}$ with age, with mid-visible $\alpha_{s}$ values for aged smoke ranging from $3.5-4.2 \mathrm{~m}^{2} \mathrm{~g}^{-1}$ (roughly $20 \%$ larger than fresh smoke with an equivalent flaming/smoldering contribution).

There is significant wavelength dependence to light scattering smoke particles, and hence $\alpha_{s}$. This is discussed in detail by Reid et al. (1998b), Eck et al. $(1999,2001)$ and O'Neill et al. (2002). Typically, $\alpha_{s}$ changes from green midvisible light by approximately $\pm 50 \%$ for blue and red wavelengths, respectively. The spectral dependence of the aerosol optical thickness (AOT) is frequently parameterized through the particle Angstrom exponent that is computed from the Ångstrom relation (Ångstrom, 1929):

$\tau_{a}=\tau_{o} \lambda^{-\alpha}$

where $\alpha$ is the Ångstrom exponent, $\lambda$ the wavelength in $\mu \mathrm{m}$ ), and $\tau_{o}$ the optical depth at $\lambda=1 \mu \mathrm{m}$. Because the wavelength dependence of the AOT does not follow Eq. (4) exactly, $\alpha$ can be computed for any sub-range using the expression:

$\alpha_{\lambda_{1}, \lambda_{2}}=-\frac{\ln \left(\tau_{\lambda_{1}} / \tau_{\lambda_{2}}\right)}{\ln \left(\lambda_{1} / \lambda_{2}\right)}$

Examples of the wavelength dependence of $\alpha$ can be found in Fig. 1a where normalized spectral AOT for fresh, aged and well-aged smoke from boreal/temperate forest burning is presented. Typically, values are on the order 2-2.5 for fresh smoke (Reid et al., 1998b; Eck et al., 1999, 2001; O'Neill et al., 2002). Particle growth during the aging process decreases the Ångstrom exponent as much as one, i.e., reduced wavelength dependence of $\alpha_{s}$ (Holben, et al., 1996b; Liousse et al., 1995; Reid et al., 1998b, 1999; Eck et al., 1999, 2001; O'Neill et al., 2002). Because the wavelength dependence of scattering and extinction shows more curvature than Eq. (4), the application of Eq. (4) can be problematic. Figure $1 \mathrm{~b}$ presents scatter plots of particle Ångstrom 
exponent (i.e., Log derivative) versus the second derivative for two sites in Africa and South America for smoky conditions (based on data from Eck et al., 1999, 2001) to demonstrate how much curvature exists. Curvature is greater for the Amazonia smoke in Bolivia due to greater particle size and less absorption than the African savanna smoke in Zambia. If the wavelength/optical depth relationship were linear, the second derivative should be close to zero. However, usually AOT deviates considerably from the Ångstrom parameterization, particularly at shorter wavelengths. Purely empirical fits that extract information from this curvature can be found in Eck et al. (1999).

It is noteworthy that variability is typical with regards to measurements of $\alpha_{s}$. There are several reasons for this. Most importantly, fires are dynamic by nature and one particular forest fire can have combustion, and therefore particle properties, significantly different from the next. Given how few measurements of $\alpha_{s}$ are actually made, a $\pm 20 \%$ variance should be considered relatively good. Second, $\alpha_{s}$ is a difficult measurement to make even under optimum conditions, and requires the proper correlation between two independent instruments (this is particularly difficult in an aircraft). Nephelometers have errors associated with them, such as those associated with truncation and non-lambertian light sources which must be corrected for (e.g., Anderson et al., 1996b). Mass measurements should not be treated as trivial. Ultimately it becomes an issue of how individual investigators collect and treat data. It is noteworthy, however, that values for $\alpha_{s}$ in the literature are fairly consistent, and measurements made in the early 1970's (e.g., Vines, 1971; Eccleson et al., 1974; Evens et al., 1976), have not systematically changed over time despite advances in techniques.

\subsection{Hygroscopicity}

When the relative humidity (RH) rises above $\sim 40 \%$, even weakly soluble aerosol particles can absorb water from the air (Orr et al., 1959). This additional water increases the particle size and thus increases the particle scattering crosssection. When very soluble particles (such as sea-salt and sulfates) are exposed to high $\mathrm{RH}(>70 \%)$, the particle scattering cross section increases by more than a factor of two.

The hygroscopic growth function, $f(\mathrm{RH})$, is a multiplicative factor which describes the degree to which light scattering by particles increases as a function of ambient $\mathrm{RH}$. The hygroscopic growth factor, often taken at $\mathrm{RH}=80 \%$ for reference $(f(80 \%))$, is defined as the ratio of light scattering by the aerosol at a $\mathrm{RH}$ of $80 \%$ to the light scattering of the dry aerosol, usually at $\mathrm{RH}<35 \% ; \sigma_{s}(\mathrm{RH}=80 \%) / \sigma_{s, d r y}$ and is frequently formulated as in Kasten (1969): $f(\mathrm{RH})=(1-$ $\mathrm{RH} / 100)^{-\alpha}$, where $\mathrm{RH}$ is in percent, and $\alpha$ is an empirical growth fitting parameter. The values of $\alpha$ range from 0 for insoluble particles to almost 1 for highly soluble species. While this formulation is based on physics of highly soluble salts, other strictly empirical formulations have been used to improve the curve fit for species without such sharp deliquescence points, such as organics (e.g., Kotchenruther and Hobbs, 1998).

Kotchenruther and Hobbs (1998) (hence KH98) presented one of the first complete data sets of direct hygroscopicity measurements of smoke particles. For fresh smoke particles, $f(\mathrm{RH})$ was found to be extremely low without significant wavelength dependence. Typically $f(\mathrm{RH})$ was $\sim 1.1$ for RH values below $80 \%$, with growth constants ( $\alpha$ using Kasten's formalism) on the order of 0.05 . However, $f(\mathrm{RH})$ increased for more aged smoke, reaching values as high as 1.35 for $80 \% \mathrm{RH}$ in smoke plumes unaffected by other species $(\alpha \approx 0.15)$. This is consistent with the secondary production of more hygroscopic particle phase species such as organic acids and sulfate.

More recently, Magi and Hobbs (2003) (hence MH03) using the same instrument as KH98, found higher values of $f(\mathrm{RH})$ at $80 \% \mathrm{RH}$ for African savanna plumes, on the order of 1.6 and 1.4 for fresh and aged smoke, respectively. Not only are these considerably higher than KH98, but $f(\mathrm{RH})$ has lower values for older plumes, opposite to KH98. MH03 attributes decreases in $f(\mathrm{RH})$ through chemical changes in the particles during the first minutes after emission. But why would such reactions not occur in South America? It can be argued that in Africa there may be additional pollution that would increase the net hygroscopicity of the measured aerosol. However, given that this large difference is present for fresh smoke, this issue becomes more troubling.

Scattered reports of larger hygroscopicity inferred from other measurements tend to support the higher values of $f(\mathrm{RH})$ from MH03. Two days of hygroscopicity data collected in Australia and Indonesia, respectively, have also been published by Gras et al. (1999). For Australian brush, the range of $f(80 \%)$ for fresh smoke, 1.2-1.6 with a mean of 1.37, was higher than Kotchenruther and Hobbs (1998). Similarly, a value of $\mathrm{f}(80 \%)$ was infered for a well aged smoke plume by Fermenti et al. (2002). For Indonesian smoke, Gras et al. (1999) found $f(80) \%$ values significantly higher, ranging from 1.5 to 2.2 with a mean of 1.65. Higher hygroscopicity was also inferred from Sun photometer data by Kreidenweis et al. (2001) for Mexican smoke. However, those cases that have been associated with the presence of large haze particles transported along with polluted airmasses or sea salt, or generated from peat burning should not be ignored (e.g., Nakajima et al., 1999; Langmann and Graff, 2003). The implications of this uncertainty are large - a relative $20-30 \%$ error in optical depth. If there are significant differences between South America and Africa (i.e. the difference is physical and not due to instrumentation errors in either KH98, or MH03, or both, a likely Ockham's Razor candidate), then the mechanism is mostly unknown and requires much research.

First, the lack of hysteresis data for smoke particle hygroscopicity is probably the most significant lapse in the literature. Both the KK98 and MH03 data are supposed to be for the lower or "initially dry" part of the curve. As much smoke 
is often in the tropics that tend to be humid (e.g., Central America, South America, Southeast Asia, wintertime tropical Africa), there does not exist any firm parameterization for the upper hygroscopic growth curve most likely to be followed by smoke. This issue is somewhat mitigated in that smoke particles have comparably small growth factors and, as organics, the hysteresis effect is likely to be smaller than a strongly deliquescing species such as pure sulfate. It is conceivable that the differences between KH98 and MH03 can be attributable to particle hysteresis. For example, KH98 cases were taken in a very humid Brazilian environment and the particles may not have fully dried out at $35 \% \mathrm{RH}$ (compared to $20 \%$ for MH03).

\subsection{Up-scatter fraction}

Once the total amount of light scattering or optical depth is established in a smoke plume, we can proceed to determine, $\bar{\beta}$, the fraction of light that is scattered back to space (effectively cooling the atmosphere). More sophisticated models typically rely on the asymmetry parameter, g, to parameterize the scattering phase function

$\mathrm{g}=\frac{\int_{-1}^{1} \mu \overline{\mathrm{P}} d \mu}{\int_{-1}^{1} \overline{\mathrm{P}} d \mu}$

where $\mathrm{P}$ is the phase function and $\mu=\cos \theta$. Physically, the asymmetry parameter is the normalized integral of the cosine weighted phase function, and is $1 / 3$ of the first term of the Legendre polynomial expansion of the phase function. The asymmetry parameter has the useful properties that: at $\mathrm{g}=1$ the scattering is completely forward (all scattering at $\theta=0^{\circ}$ ); at $\mathrm{g}=-1$ scattering is completely backward (all the scattering is at $\theta=180^{\circ}$ ); and at $\mathrm{g}=0$, there is symmetric scattering (i.e., isotropic, Rayleigh or dipole radiation).

One of the more significant gaps in the global biomass burning data set relates to the direct measurement of scattering phase function and the up-scattering parameters (although it must also be said that they are easily computable). To our knowledge there does not exist a direct measurement of smoke particle phase functions or asymmetry parameters in the peer-reviewed literature (although, as will be discussed in following sections, theoretical and inversion derived values do exist). Such a measurement would require the use of a polar nephelometer, for which few published observations have been made.

A partial substitute for $\bar{\beta}$ or g can be measured through the use of a backscatter shutter on a nephelometer. The hemispherical backscatter ratio, $\beta(\cos \mu=1)$ or simply $\beta(1)$, is defined as the ratio of backscattered light to total scattered light along a ray path, and is equivalent to the atmospheric up-scatter fraction for an optically thin non-absorbing atmospheric aerosol layer when the sun is directly overhead.

Values for $\beta(1)$ can be measured relatively easily now with commercially available nephelometer systems, and are just starting to appear in the literature. Tables 1 and 2 list values for $\beta(1)$ collected for fresh and aged smoke in Africa and Brazil. For small size parameters such as Rayleigh scattering, $\beta(1)$ takes a value of 0.5 , with equal scattering in the forward and backward directions. For fresh smoke, values for $\beta(1)$ are on the order of $0.15,0.18$ and 0.21 for blue, green, and red wavelengths, respectively (Reid and Hobbs, 1998; Reid et al., 1998b). Values for $\beta(1)$ are closely related to size for particle size distributions similar to those found in smoke: as particles size parameters increase, $\beta(1)$ decreases. Consequently, larger particles associated with aged and smoldering combustion have lower values for $\beta(1)$, on the order of $0.11,0.12$ and 0.14 for blue, green, and red wavelengths, respectively (Reid et al., 1998b; Iziomon and Lohmann, 2003). Eventually, $\beta(1)$ values reach a theoretical limit of $\sim 0.10$ for commonly assumed refractive indices (see Sect. 3). Particle hygroscopicity also reduces the backscatter ratio of aged particles on the order of $\sim 0.02$ from dried to $80 \% \mathrm{RH}$ conditions (KH98 and MH03).

A problem in radiative transfer is how to relate the easily measurable parameter $\beta(1)$ to the daily average up-scatter fraction and g, and hence estimate the net up-scatter fraction of the atmosphere. To do this we need to measure (or assume) some form of the aerosol phase function. For the commonly used Henyey-Greenstein phase function, $\beta(1)$ of $0.2,0.15$ and 0.11 correspond to $g$ values of $0.44,0.54$ and 0.63 , respectively. Given that smoke particles grow to a size such that the 0.10 limit is reached, a $g$ value of $\sim 0.63$ is likely a good choice for radiative transfer calculation for aged smoke. Continuing along these lines, to determine the daily averaged up-scatter fraction of solar radiation needed for Eq. (1), we can apply the two-stream methodology of Wiscombe and Grams (1976). From this, we derive daily averaged up-scatter backscatter fractions of $\bar{\beta}$ of $0.31,0.28$ and 0.24 to correspond to $\mathrm{g}$ values of $0.44,0.54$ and 0.63 above. While a simple exercise, these values are nonetheless consistent with forward modeling and inversion methods discussed later.

\subsection{Mass absorption efficiency and single scattering albedo}

Just as a mass scattering efficiency was defined in Sect. 2.1, an analogous form for the mass absorption efficiency, $\alpha_{a}$ $\left(\mathrm{m}^{2} \mathrm{~g}^{-1}\right)$, can be defined as $\sigma_{a}=\alpha_{a} \cdot \mathrm{c}_{m}$ where $\sigma_{a}$ as the absorption coefficient $\left(\mathrm{m}^{-1}\right)$ and $\mathrm{c}_{m}$ is the aerosol mass concentration $\left(\mathrm{g} \mathrm{m}^{-3}\right)$. However, the intensive parameter most frequently used to model absorption in the atmosphere is not $\alpha_{a}$ but rather the single scattering albedo $\left(\omega_{o}\right)$, defined as the ratio of total light scattering to total extinction, $\omega_{o}=\sigma_{s} /\left(\sigma_{s}+\sigma_{a}\right)=\alpha_{s} /\left(\alpha_{s}+\alpha_{a}\right)$. Note here that, unlike scattering, there is no hygroscopic growth term for absorption, as it tends to be small and usually neglected by the community. Redemann et al. (2001) found absorption hygroscopic growth values as high as 1.215 for $80 \% \mathrm{RH}$ for sulfates. For 
Table 2. In situ measurements of optical properties of aged regional smoke.

\begin{tabular}{|c|c|c|c|c|c|c|}
\hline Reference & \# & $\lambda(\mathrm{nm})$ & $\alpha_{s}$ & $\alpha_{a}$ & $\omega_{o}$ & $\beta$ \\
\hline \multicolumn{7}{|l|}{ Africa } \\
\hline Abel et al., (2003) & 1 & 550 & & & 0.90 & \\
\hline Haywood et al. (2003)* & many & 567 & & & $0.91 \pm 0.04$ & \\
\hline Pilweskie et al. (2003) & 2 & 450 & & & $0.85-0.88$ & \\
\hline Pilweskie et al. (2003) & 2 & 550 & & & $0.84-0.88$ & \\
\hline Pilweskie et al. (2003) & 2 & 700 & & & $0.76-0.87$ & \\
\hline Formenti et al. $(2003) * \%$ & many & 567 & $\sim 4.2-4.6$ & & $0.93 \pm 0.06$ & \\
\hline Magi et al. (2002)* & many & 567 & & & $0.83 \pm 0.02$ & \\
\hline \multicolumn{7}{|l|}{ North America } \\
\hline Iziomon and Lohman (2003)* & many & 567 & & & $0.91 \pm 0.04$ & $0.14 \pm 0.03$ \\
\hline \multicolumn{7}{|l|}{ South America } \\
\hline Artaxo et al. (1994) & $\sim 150$ & WL & & $\sim 1.1$ & & \\
\hline Artaxo et al. $(1998)^{\&}$ & $\sim 60$ & WL & & $0.5 \pm 0.2$ & & \\
\hline Echalar et al. (1998) & 126 & WL & & $0.9-1.1$ & & \\
\hline Guyon et al. (2003) & many & & & & $0.89 \pm 0.02$ & $0.10 \pm 0.02$ \\
\hline Hobbs et al. (1997)@ & 62 & 550 & $3.3 \pm 0.75$ & & $0.84 \pm 0.04$ & $0.11 \pm 0.02$ \\
\hline Martins et al. (1998)\& & 20 & WL & & $0.45 \pm 0.2$ & & \\
\hline Reid et al. (1998b) ${ }^{\%}$ & 62 & 450 & $5.2 \pm 1.5$ & & & $0.11 \pm 0.01$ \\
\hline Reid et al. $(1998 b)^{\%}$ & 62 & 550 & $4.1 \pm 0.9$ & $0.7 \pm 0.2$ & $0.86 \pm 0.05$ & $0.11 \pm 0.01$ \\
\hline Reid et al. $(1998 b)^{\%}$ & 62 & 700 & $2.4 \pm 0.6$ & & & $0.16 \pm 0.01$ \\
\hline \multicolumn{7}{|l|}{ Canada to Europe } \\
\hline Formenti et al. (2002) & many & 450 & & & 0.91 & \\
\hline Formenti et al. (2002) & many & 550 & & & 0.89 & \\
\hline Formenti et al. (2002) & many & 700 & & & 0.85 & \\
\hline
\end{tabular}

* These studies used continuous reading Particle Soot Absorption Photometer (PSAP) data.

\# Bergstrom et al. (2003) also show the same data. Both manuscripts present $\omega_{o}$ values for the entire solar spectrum. Sample wavelengths are given here.

$\&$ These two studies use the same samples and raw values but different apportionment techniques.

@ These values are superseded by Reid et al. (1998).

$\%$ Mass scattering efficiency data is for accumulation mode particles only.

particles with hygroscopicity similar to smoke, this would reduce to a maximum $8 \%$ correction.

There are two principle methodologies that are commonly employed to determine $\sigma_{a}$ of smoke particles. The most direct method involves measuring the optical characteristics of the aerosol, usually by measuring the attenuation of a light beam through a sample, which can either be in the atmosphere (extinction cell, cavity ring down etc.) or be collected on a filter (reflectance techniques, Particle Soot Absorption Photometer - PSAP, integrating plate, etc.). Alternatively, it is often assumed that black carbon is the only absorber of light in the aerosol particles and therefore, $\sigma_{a}$ can be estimated by employing a value for mass absorption efficiency of black carbon $\left(\alpha_{a b c}\right): \sigma_{a}=\alpha_{a b c} \cdot c_{m b c}$, where, $c_{m b c}$ is the mass concentration of black carbon. Hence, through a mass fraction measurement of black carbon, $\sigma_{a}$ can be estimated. This later method is not a true measurement per se, and we will discuss it further in Sect. 3.
The measurement of absorption (either $\sigma_{a}$ or $\alpha_{a}$ ) is the most difficult, and hence contentious parameter of the radiative bulk properties. There has been considerable debate as to which methods, if any, yield correct results (e.g., Clarke et al., 1987; Campbell et al., 1996; Heintzenberg et al., 1997; Reid et al., 1998a; Russell et al., 2002). Although extinction type cells are probably the most accurate for measurement of in situ absorption, (Heintzenberg et al., 1997), typically $\sigma_{a}$ is small relative to $\sigma_{s}$. Determining $\sigma_{a}$ by subtracting nephelometer derived scattering from extinction cell derived extinction (e.g., Radke et al., 1991; Hobbs et al., 1996; Reid and Hobbs, 1998) involves the subtraction of two large numbers and can be uncertain in low absorption environments. Consequently, for biomass burning research, extinction cells have generally been used in thick individual smoke plumes.

For regional smoke, where classical extinction cells cannot be used, the determination of $\sigma_{a}$ through the measurement of transmission or reflectance of a filter sample is often 
substituted; given that there are enough samples taken to reduce noise (e.g., Artaxo et al., 1994; Reid et al., 1998b; Bond et al., 1999). Each method needs a set of calibrated response function curves (e.g., Bond et al., 1999). The difficulty is that divergence develops in the literature since each investigator performs the analysis differently. The advantage of these methods is that samples can be collected en masse, and that data from both fresh smoke plumes and regional smoky hazes can be compared on fairly equal footing. For example, using an optical reflectance technique on polycarbonate filter samples, very large and consistent datasets of smoke absorption can be developed (e.g., Artaxo, 1994, 1998; Martins et al., 1996; Yamasoe et al., 2000).

Values for published measurements of $\alpha_{a}$ and $\omega_{o}$ for fresh and aged smoke are included in Tables 1 and 2. For green or white light, there is a fair amount of consistency in reported $\alpha_{a}$ values. For flaming combustion (regardless of fuel types), values of $\alpha_{a}$ are typically in the 1 to $1.4 \mathrm{~m}^{2} \mathrm{~g}^{-1}$ range, although individual samples from black smoke plumes from very intense fires have been measured with values as high as $3 \mathrm{~m}^{2} \mathrm{~g}^{-1}$ (e.g., Martins et al., 1996; Reid and Hobbs et al., 1998). As these fires transition to mixed and eventually fully smoldering combustion, black carbon production is drastically reduced. Consequently the mass absorption efficiency reduces in magnitude as well. Measurements of $\alpha_{a}$ fall off to a range of 0.6 to $1.0 \mathrm{~m}^{2} \mathrm{~g}^{-1}$ for mixed phase combustion, and decline further to the 0.2 to $0.7 \mathrm{~m}^{2} \mathrm{~g}^{-1}$ range for plumes dominated by smoldering combustion, consistent with the reduction of black carbon production. Purely smoldering combustion yields values of $<0.3 \mathrm{~m}^{2} \mathrm{~g}^{-1}$ (see samples in Radke et al., 1991; Hobbs et al., 1996; Martins et al., 1996).

Reports of in situ single-scattering albedo measurements of fresh smoke from extinction cells are mostly consistent with reported mass scattering and mass absorption efficiencies from filter-based methods. Given a mean $\alpha_{s}$ value of $3.4 \mathrm{~m}^{2} \mathrm{~g}^{-1}$, and a mean $\alpha_{a}$ value of $\sim 1.1 \mathrm{~m}^{2} \mathrm{~g}^{-1}$ for flaming phase dominant combustion, we would expect a mean $\omega_{o}$ value of $\sim 0.75$ (note here we are using only independent measurements of absorption and single scattering albedo). Similarly, given a mean $\alpha_{s}$ value of $3.7 \mathrm{~m}^{2} \mathrm{~g}^{-1}$, and a mean $\alpha_{a}$ value of $\sim 0.4 \mathrm{~m}^{2} \mathrm{~g}^{-1}$ for more smoldering prevalent combustion, we would expect a mean $\omega_{o}$ value of $\sim 0.90$. Collected fire data follows similarly with mid-visible $\omega_{o}$ values increasing from 0.65 to 0.85 in ignition/flaming to values of 0.8 to 0.9 and 0.88 to 0.99 for mixed phase and smoldering phase combustion, respectively (Radke et al., 1988, 1991; Hobbs et al., 1996; Reid and Hobbs, 1998).

There are systematic differences in $\omega_{o}$ values measured on different continents due to different fuel types and burning conditions. For example, North American forest fires tend to have higher $\omega_{o}$ values on the order of $0.80-0.85$ for flaming phase combustion, compared to $\omega_{o}$ values on the order of 0.75 to 0.8 for tropical forest fires of similar combustion efficiency. However, $\alpha_{a}$ values for flaming combustion for the two regions are similar at $\sim 0.9-1.1 \mathrm{~m}^{2} \mathrm{~g}^{-1}$. Hence, this dif- ference in $\omega_{o}$ is attributed to the differing mass-scattering efficiencies. As discussed in the previous section, North American fires tended to have higher $\alpha_{s}$ values than the South American tropical fires due to difference in mean particle size, and more smoldering combustion (larger size implies higher $\alpha_{s}$ ). This difference in size and temperature translates into a higher $\omega_{o}$ value for temperate and boreal fires. In Africa, with flaming phase savanna fires being more prevalent, we expect a higher value of $\alpha_{a}$ and subsequently lower $\omega_{o}$.

There are reports of fires with very high absorption values. Reid and Hobbs (1998) took several samples of an intense mixed grass/slash fire with $\omega_{o}$ values on the order of 0.3 to 0.5 . This is near the theoretical limit where light scattering is heavily dominated by diffraction only. All absorption measurements made at this time (extinction cell, PSAP, integrating plate, optical reflectance and black carbon measurements) were in agreement with these values. Further, the high $\alpha_{a}$ vales reported by Yamasoe et al. (2000) would suggest $\omega_{o}$ values on the order of 0.6 are not atypical. It is likely these extreme absorption events occur in the late ignition and early flaming phases of combustion. Time series of particle properties presented by Radke et al. (1991) and Martins et al. (1996) show the extremely high mass absorption efficiencies in the earliest stages of the fire.

Reports of absorption properties of aged and regional smoke suggest a significant decrease in smoke particle $\alpha_{a}$ and an increase in $\omega_{o}$ with time. Typically, well-aged smoke has optical properties similar to fresh particles from smoldering combustion. For example, Reid et al. (1998) found smoke aged for several days had dry $\omega_{o}$ values on the order of 0.86 . Compare this to the values of 0.84 Reid and Hobbs (1997) found for smoldering phase particles from tropical forest. For an individual fire, Abel et al. (2003) observed an increase in $\omega_{o}$ by 0.04 in two hours (from 0.84 to 0.88 ), and by 0.06 in 5 hours (from 0.84 to 0.90 ) due to the condensation of organic matter. Radke et al. (1995) and Hobbs et al. (1996) also found similar but less quantitative trends for several temperate fires (see Table 66.3). Aged smoke particles have reported $\alpha_{a}$ values on the order of $0.5-1 \mathrm{~m}^{2} \mathrm{~g}^{-1}$. There are at least two possible mechanisms for increases in $\omega_{o}$ with time. First, one must consider sample bias. As regional smoke ages, it can be enriched by smoke from other fires. Often, deforestation fires can smolder for days, producing particles at high emission factor rates with little or no black carbon. These fires are rarely measured and, given sufficient numbers, they can produce large quantities of non-absorbing particles, thereby increasing the mean single scattering albedo. Hence, concurrent $\mathrm{CO}$ and $\mathrm{CO}_{2}$ measurements are highly desirable to determine the mean combustion efficiency of the original smoke. Second, particle growth mechanisms converge to increase $\omega_{o}$ and decrease $\alpha_{a}$. Particle growth mechanisms (such as coagulation and condensation) increase the mass-scattering efficiency of the particles. This not only due to increase in size, but also the collapse of any chain aggregates (Abel et al., 
2003). Hence even if $\alpha_{a}$ were static during aging, $\omega_{o}$ should increase in time. Gas-to-particle conversion mechanisms decrease the mass fraction of black carbon and hence decrease $\alpha_{a}$. Since most of this secondary mass production occurs due to condensation in the early stages of plume evolution (Reid et al., 2004), the decrease in $\alpha_{a}$ likely occurs rapidly as well.

Spectral dependence measurements of absorption are extremely rare in the literature, and typically a $1 / \lambda$ to $1 / \lambda^{2}$ wavelength dependence is assumed. Only recently have in situ measurements of the spectral dependence of aged smoke, $\omega_{o}$, appeared in the literature. Pilewskie et al. (2003) and Bergstrom et al. (2003) used a flux divergence method to derive $\omega_{o}$ over the range of $0.35-1.6 \mu \mathrm{m}$ for two aged smoke cases over Africa. Mean $\omega_{o}$ ranged from $0.88-0.9$ at $350 \mathrm{~nm}$, to $0.82-0.86$ at $550 \mathrm{~nm}, 0.6-0.85$ at $850 \mathrm{~nm}$ - within the commonly used $1 / \lambda$ to $1 / \lambda^{2}$ assumption. As African smoke tends to have a higher black carbon content than most other regions, these values should be considered to be slightly lower than the global mean.

As will be demonstrated in later sections, there is a significant systematic difference between in situ measurements (such as those presented here), and values inferred from radiometric techniques. In situ values of $\omega_{o}$ for regional hazes and plumes are typically $\sim 0.05$ lower than those derived by satellite, Sun photometry, and flux based retrievals. This has led some investigators to credibly argue that most in situ methods consistently over estimate absorption (most notably Clarke et al., 1987; Heintzenberg et al., 1997; Reid et al., 1998a; Bond et al., 1999, and Russell et al., 2002). Correction factors that have been put forth have gained acceptance by the scientific community and, consequently, reported values of $\omega_{o}$ are beginning to rise to values comparable to the remote sensing derivations (e.g., Guyon et al., 2003; Formenti et al., 2003; Haywood et al., 2003b). Thus, previous in situ reports, like those shown in Table 1 and 2, are often taken as lower limits of possible $\omega_{o}$ values. As an example, the filter measurements in Reid et al. (1998a) were validated against an active extinction cell. However, this was performed in dense dark plumes with a mean $\omega_{o}$ value of 0.75 . For less absorbing species, the scattering corrections of Bond et al. (1999) become more applicable. Therefore, the values for less absorbing regional haze should increase by $\sim 0.02$ in the mid visible. Similar corrections can be made to most in situ measurements. But even with these corrections, $\omega_{o}$ still tends to be lower than from remote sensing derivations.

\section{Direct forward methods}

The disadvantage of bulk methods is that they are strictly empirical, and hence cannot make full use of information from microphysical, radiative and transport models, nor be extrapolated to other wavelengths or from other measurements. Conversely, they are a powerful constraint on the system.
The optical properties of smoke are often estimated through direct computational methods, with investigators putting the particles' geometric size distribution and the real and complex indices of refraction for each size bin into a Mie Theory model. Bulk particle size distribution measurements are available, and sphericity and homogeneity (internal mixing) are often assumed. Many use a coated sphere model where a black carbon core is surrounded by a non-absorbing organic shell.

As discussed briefly above and Reid et al. (2004), smoke accumulation mode particles are spherical in nature and are typically modeled as such. Even in intense burning conditions when chain aggregates and other asymmetric particles are created, particle evolutionary processes converge to create more spherical particles (e.g., Martins et al., 1996; Hobbs et al., 1996). But, near the fire source particle asymentry can have some impact on particle properties. While aerosol extinction efficiency is more or less conserved, aggregation can increase total scattering relative to absorption, increase the asymmetry parameter, and depolarize scattered light (Ku and Shim, 1992; Colbeck et al., 1997; Sorensen, 2001). Consequently, such particles cannot be modeled as equivalent spheres. The interested reader is referred to the thorough Sorensen (2001). For the rest of this section, however, we assume a fairly justifiable spherical type model.

Many forward modeling and internal/external "column closure" calculations for biomass smoke have been presented in the literature in which reasonably good "closure" has been achieved using sphere/coated sphere models. For example, Martins et al. (1996) and Reid and Hobbs (1998) found agreement in the modeled and bulk properties for fresh North American and South American smoke, respectively. Similarly, Anderson et al. (1996a) and Ross et al. (1998) derived mid visible mass scattering efficiency and singlescattering albedo values for aged smoke in Brazil that were close to field measurements (Reid et al., 1998b). Haywood et al. (2003ab) also had little difficulty in making similar internal closure calculations that match other observations for Africa in SAFARI2000. Using an iterative process Guyon et al. (2003) also derived "reasonable" closure. However, upon close examination, such consistency between models and measurements is not too difficult to achieve. The crux of the forward modeling problem lies in the relatively high degree of variability of poorly constrained input parameters, particularly the treatment of particle size, density, complex index of refraction and black carbon.

It is well established that mass absorption efficiency for black carbon, $\alpha_{a b c}$, can theoretically be highly variable, with values on the order of $5-25 \mathrm{~m}^{2} \mathrm{~g}^{-1}$ for coated spheres compared to the nominal values of $5-10 \mathrm{~m}^{2} \mathrm{~g}^{-1}$ for solid black carbon particles (e.g., Chylek and Wong, 1995; Martins et al., 1998a - see Fig. 3). This efficiency is strongly tied to volume fraction, mixing, and size distribution. But, as discussed in the companion paper Reid et al. (2004), black carbon estimates are highly uncertain and errors on the order 

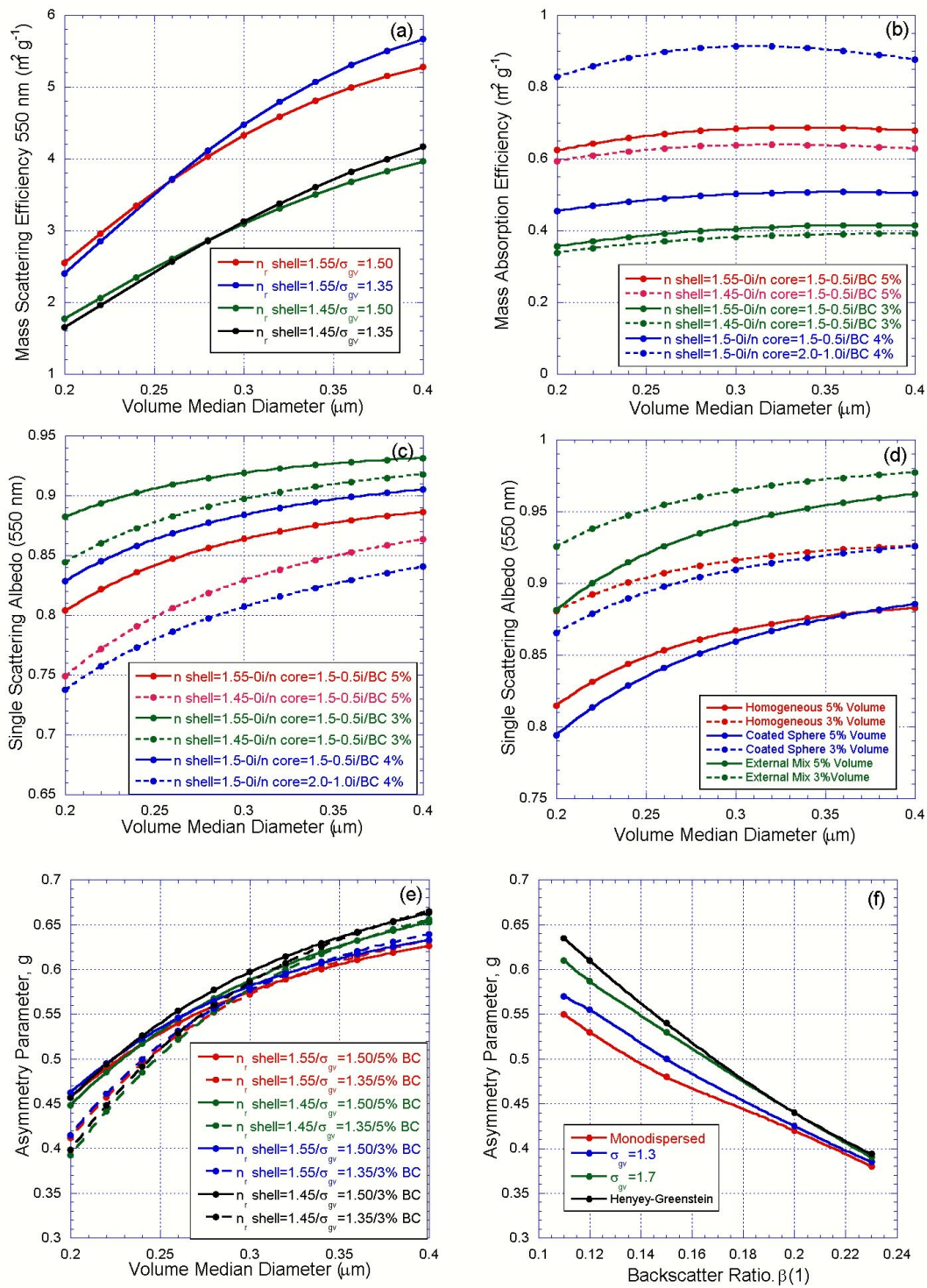

Fig. 2. Intercomparison of key radiative parameters as a function of particle microphysical properties at $550 \mathrm{~nm}$. (a) Mass scattering efficiency as a function of volume median diameter (VMD), geometric standard deviation $\left(\sigma_{g v}\right)$ and shell index of refraction $\left(\mathrm{n}_{r}\right.$ shell) for a particle with 5\% volume fraction of black carbon (BC). (b) Single scattering albedo as a function of VMD, $\mathrm{n}_{r}$ shell, and BC volume fraction (for $\sigma_{g v}=1.5$ ), (c) Single scattering albedo as a function of physical model, (d) Mass absorption efficiency as a function of VMD, $\sigma_{g v}, \mathrm{n}_{r}$ shell and BC volume fraction. (e) Same as (d) for asymmetry parameter, g, (f). Asymmetry parameter as a function of hemispheric backscatter ratio for phase functions assuming various $\sigma_{g v}$.

of $50 \%$ are not unexpected. Although size distribution parameters are fairly well known, the modeling studies listed above have shown that even a small uncertainty can have a significant effect on estimated absorption and scattering efficiencies. This effect can be compounded by the choice of internally homogenous, core/shell, or externally mixed models.

The complexity of $\alpha_{a b c}$ makes the application of absorption measurements to infer black carbon concentrations problematic. For example, the papers of Artaxo et al. (1994,
1998) use a reflectance technique to derive their values for black carbon concentration using a static mass absorption efficiency of $6.8 \mathrm{~m}^{2} \mathrm{~g}^{-1}$. Martins et al. (1998) and Reid et al. (1998a) then logically found that while this method was poorly correlated to actual measurements of black carbon, its values were very good for making estimates of absorption. Methods such as this are essentially circular, and the true nature of black carbon is still uncertain. These studies suggest that measurements of black carbon should be treated as an entirely separate entity from absorption measurements. 
Once a physical model is chosen, uncertainty is further increased by the selection of smoke particle index of refraction and density. Suggested indices of refraction for black carbon in forward calculations have included 2.0-1.0i to 1.90.5i (Janzen, 1980), 1.8-0.5i (Chang and Charalampopoulos, 1990), 1.75-0.45i (Shettle and Fenn, 1979; WCP, 1986), and 1.5-0.5i (Horvath, 1993), with lower values of the complex portion being in more favor with the scientific community. Even so, it must be remembered that these values are not based on actual measurements of particle refractive index per se, but rather are inferred from their own "closure" calculation of particle size, scattering, and absorption measurements. For particles larger than $\sim 0.4 \mu \mathrm{m}$ in diameter, these differences in refractive index do not appear to be significant (Martins et al., 1998a). However, for particles $<0.3 \mu \mathrm{m}$ in diameter (which account for the bulk of the light scattering) such variability in black carbon refractive index can induce a $20-40 \%$ change in absorption. Equal variability exists for the index of refraction of the smoke particle shell. It is often assumed that black carbon is the only absorber, and that the particle shell has only a 0 complex index of refraction. Mulholland et al. (1985) was one of the early studies on this topic and found that for smoldering cellulose, an invariant value of 1.5 was appropriate. Similar results for mid-wave/longwave IR for alfalfa hay/dried grasses were found by Sutherland and Khanna (1991). Since then, various values ranging from 1.42 to 1.55 for the real part of the refractive index have been suggested, again through "closure" type studies (see Guyun et al., 2003, for a list). To scale the correct bulk index of refraction between the core and coating, density corrections need to be applied to derive the correct volume ratio. Densities on the order of $1.7-2.3 \mathrm{~g} \mathrm{~cm}^{-3}$ and 1 to $1.4 \mathrm{~g} \mathrm{~cm}^{-3}$ are often assumed for black carbon and shell, respectively, with these values alone leading to a $40 \%$ variance in the calculation of $\alpha_{s}$ (Reid et al., 2004). As black carbon is intermixed with other refractory material in the particle core (such as potassium), the true cross-section is probably larger than what these densities would suggest. Haywood et al. (2003a, b) assumed a value of $1.7 \mathrm{~g} \mathrm{~cm}^{-3}$ to compensate for this effect, but even this is very uncertain.

To demonstrate the high degree of freedom in the selection of these parameter values, particle mass scattering efficiency $\left(\alpha_{s}\right)$ and single scattering albedo $\left(\omega_{o}\right)$ as a function of variable size and index of refraction is shown in Fig. 2. Particle mass scattering efficiency as a function of particle volume median diameter (VMD), geometric standard deviation $\left(\sigma_{g v}\right)$, and shell index of refraction is given in Fig. 2a. Here we assume a lognormal coated sphere model and assume a $5 \%$ black carbon volume fraction for each size. Black carbon has a complex index of refraction of 1.5-0.5i (the smallest in the range commonly used). These curves demonstrate the factors involved in determining $\alpha_{s}$. Most important is particle volume median diameter. For VMDs in the 0.25 to 0.35 range (which covers most commonly found values), $\alpha_{s}$ can shift on the order of $40 \%$, or roughly $8 \%$ to $2 \%$ per
$0.01 \mu \mathrm{m}$ increase in diameter for smaller and larger particles respectively. Reid et al. (1998b) found in side-by-side comparisons of the PCASP and a differential mobility particle sizer (DMPS) that the DMPS gave values for VMD and $\sigma_{g v}$ of $\sim 0.04 \mu \mathrm{m}$ larger. These differences would result a $20 \%$ variation in $\alpha_{s}$.

Geometric standard deviation, however, does not appear to make too significant an impact. A shift of $\sigma_{g v}$ from 1.5 to 1.35 is enough to increase $\alpha_{s}$ by only a few percent due to a crossover point. However, this variance is well within the uncertainty of the measurement, and $\sigma_{g v}$ values higher than 1.7 have been measured. As discussed in Reid et al. (2004), there is a trend in the literature for data from the Passive Cavity Aerosol Spectrometer Probe - PCASP (a wing mounted optical particle counter) to give very narrow geometric standard deviations (on the order of 1.35) to its accumulation mode volume distributions. This is in part due to a design flaw in the placement of size bins, as well as to uncertainty in the light scattering - size relationship in the 0.3-0.5 range. Even an error in $\sigma_{g v}$ this large does not significantly alter $\alpha_{s}$ directly, though it may result in an underestimated VMD, as discussed above.

The most significant and uncertain term in determining $\alpha_{s}$ is clearly the real component of the particle index of refraction, which is not well parameterized, having suggested values from 1.43 to 1.55 . This adds an uncertainty of approximately one-third to the calculation (the index of refraction of the particle core (not shown) has very little effect). Since there are so many choices available to a researcher, fine-tuning the index of refraction by a few hundredths based on any available bulk measurements is easily done.

Next examine $\alpha_{a}$ in Fig. 2b. Here again we use a black carbon core with an index of refraction of 1.5-0.5i and $\sigma_{g v}$ of 1.5 (as for $\alpha_{s}$, shifting $\sigma_{g v}$ does not have an appreciable effect on $\alpha_{a}$ ). We also give cases for the range of $\mathrm{BC}$ indices of refraction suggested in the literature, using a median shell index of refraction of $1.5-0 \mathrm{i}$ and a BC volume fraction of $4 \%$. When one considers the recent exuberance in the scientific community over the effect of aerosol particle absorption on climate change, ultimately $\alpha_{a}$ becomes one of the most important parameters for forward modeling. Here $\alpha_{a}$ shifts only slightly due to changes in the coating index of refraction; it is the core index of refraction that is the critical intensive parameter. Choices for the core index of refraction used in the literature yield differences of a factor of two.

Variability in $\alpha_{s}$ and $\alpha_{a}$ produces a subsequent large degree of freedom in $\omega_{o}$. Consider Fig. 2c where $\omega_{o}$ is given for the same parameters as Fig. 2b. Here, we find that the index of refraction of the particle shell and core have a tremendous impact on modeled $\omega_{o}$, with changes in the shell refractive index controlling particle scattering and the core index of refraction controlling absorption. Given the field $\mathrm{min} / \mathrm{max}$ uncertainty of 0.15 in shell index of refraction, the maximum $\omega_{o}$ uncertainty is 0.05 . Further, differences in black carbon volume between $3 \%$ and $5 \%$ are also likely to be irresolvable 
when one considers the true uncertainties in black carbon measurements and density. Selection of the index of refraction of the black carbon core is equally critical, shifting $\omega_{o}$ by as much as 0.07 , similar to the effect of change in the shell refractive index.

Choices in particle mixing can also be important. The impacts of commonly used mixing parameterizations are also shown in Fig. 2d where we compare external mixing, homogenous mixing with a volume weighted index of refraction, and coated sphere. Clearly, external mixing has the largest effect and gives dramatically higher values of $\omega_{o}$ than the other two models. Repeated electron microscopy studies have demonstrated that for the most part, smoke is internally mixed (e.g., Martins et al., 1996; Reid and Hobbs, 1998; Pofasi et al., 2003) and that the external mixing model is rarely applicable. For larger particle sizes, the differences between coated sphere and homogenous sphere do not appear to cause differences $\omega_{0}$.

Lastly, we consider backscatter parameters. Figure 2e presents various values for $\mathrm{g}$ as a function of parameters listed in Fig. 2d. As can be seen, $g$ is not terribly sensitive to any parameter other than particle volume median diameter. For smaller modal diameters, narrower $\sigma_{g v}$ values result in a slightly lower g. For VMDs typical of aged smoke $(\sim 0.28$ 0.33 ), the various curves tend to intersect. The only pitfall is that if a coated sphere model is used instead of homogenous sphere, $\mathrm{g}$ drops by 0.04 . The relationship between $\mathrm{g}$ and the hemispheric backscatter ratio $(\beta(1)-$ as measured with a nephelometer - e.g., a variable that is measurable) is also fairly straightforward as long as $\sigma_{g v}$ is reasonably well known (Fig. 2f).

The point of this entire exercise is to simply point out that for the calculation of $\alpha_{s}, \alpha_{a}$, and $\omega_{o}$, almost any value can easily be derived and justified at a single wavelength using physical parameters that are commonly used. How these uncertainties can play into a field program is easily demonstrated. For example, consider that measurements of aged smoke $\omega_{0}$ for Africa taken during the SAFARI2000 using a PSAP (listed in Table 2) vary from 0.83 to 0.93 , and thus are equivalent to almost a factor of three difference in $\alpha_{a}$. Even so, these differences can easily be justified based on index of refraction parameters. For specific examples, Reid and Hobbs (1998) found agreement between measured and modeled parameters for fresh smoke using indices of refraction of $1.50-0 \mathrm{i}$ and $1.8-0.75 \mathrm{i}$ for the shell and core, respectively. Haywood et al. (1998a) found agreement between measurements and inversions using a homogenous sphere model with an mixed index of refraction of 1.53-0i for the organics and 1.75-0.44i for black carbon. Anderson et al. (1996a) assumed a homogeneous spherical model with an index of refraction of $1.55-0.03$ i. Sensitivity tests by Martins et al. (1998) assume a BC refractive index of 2.0-1.0i. Ross et al. (1998) achieved closure by deriving the black carbon content for their calculations based on a best fit mass absorption efficiency in a recursive nature, thus yielding black carbon concentrations one third less those found by Martins et al. (1998). Guyon et al. (2003) recently derived particle index of refraction of smoke of 1.41-0.013i at ambient humidity $<80 \%$, which leads us directly to the issue of the wide variety of particle hygroscopic growth factors assumed. Things become considerably more complicated for multiple wavelength studies, particularly because there is so little bulk data to validate against. Does one use a static index of refraction or vary it by wavelength? Clearly, there is an issue with consistency in the literature.

None of the issues brought up in this section are terribly new, and most forward modeling and sensitivity papers discussed in this section at least mention (if not explore in detail) the uncertainty in input parameters. Indeed, there are a whole host of relevant studies that make these arguments. We could continue a review all of the findings from each of these papers and many more in detail for many pages, with each assumption justified or refuted by a counter argument of equal merit. In the end, the result of the ensemble of all of these studies is ambiguous, with the representation of particle absorption in particular requiring extreme caution.

\section{Inversions of smoke properties}

Once the uncertainties in forward modeling are understood, the next logical step is to utilize inverse methods to derive particle size, absorption and properties from satellite, optical depth and sky radiance measurements in order to find constrained solutions. The advantage of inversion studies is that by definition, there is a high degree of "closure" and all of the retrieved properties for individual cases are, at the very least, consistent. Indeed, it is a necessary constraint. Further, these inversions give "column integrated" results that have been more useful to the satellite remote sensing and climate communities. Compared to field measurements, the method is fairly inexpensive and can be applied consistently all over the world leading to large numbers of samples. The disadvantages are that they cannot be used for individual fires or inhomogeneous skies (introducing clear sky bias), are difficult to validate, and are sometimes prone to degeneracy in solutions (i.e., several solutions that give the same sky radiance and optical depth). Hence, from the very onset, these inversions should be treated as producing "optically equivalent" sizes and optical properties that match the input radiance field and that these inversion results, at times, may differ from reality. To reduce the probability of degeneracy or retrieval of unphysical solutions, further constraints have been placed, to such a degree that it has been argued that some inversion methods can be somewhat cyclical and less independent than often portrayed. Constraints vary from simply having a smooth size distribution, to predefined indices of refraction or distribution shapes.

Most inversion methods can trace their roots back to the constrained linear inversion technique of Twomey (1965). 
Table 3. Summary of biomass burning aerosol optical properties retrieved from worldwide AERONET network of ground-based radiometers. Symbols definition: $\left\langle\tau_{a}\right\rangle-$ mean optical thickness, $\alpha$ - Ängstrom exponent, $\omega_{0}$ - single scattering albedo, $n$ and $k-$ the real and imaginary parts of the refractive index. The parameters of the bi modal log-normal particle size distribution (see Eq. 1): $\mathrm{r}_{v f}$ and VMD - volume median diameter of the fine and coarse modes, $\sigma_{g v}$ - geometric standard deviations of the fine and coarse modes, $\mathrm{C}_{v f}$ and $\mathrm{C}_{v c}-$ volume concentrations of the fine and coarse modes.

\begin{tabular}{|c|c|c|c|c|}
\hline & $\begin{array}{l}\text { Amazonian Forest: Brazil (1993-1994); } \\
\text { Bolivia (1998-1999) }\end{array}$ & $\begin{array}{l}\text { South American Cerrado: } \\
\text { Brazil (1993-1995) }\end{array}$ & $\begin{array}{c}\text { African Savanna: } \\
\text { Zambia (1995-2000) }\end{array}$ & $\begin{array}{l}\text { Boreal Forest: USA, } \\
\text { Canada (1994-1998) }\end{array}$ \\
\hline \multicolumn{5}{|l|}{ Updated Dubovik et al. (2002) } \\
\hline Number of meas. (total) & 700 & 550 & 2000 & 1000 \\
\hline Number of meas. (for $\omega_{\mathrm{w}}, \mathrm{n}, \mathrm{k}$ ) & 250 (August-October) & 350 (August-October) & 700 (August-November) & 250 (June-September) \\
\hline Range of optical thickness; $<\tau_{a}>$ & $0.1 \leq \tau 0440) \leq 3.0 ;<\tau(440)>=0.74$ & $0.1 \leq \tau 0440) \leq 2.1 ;<\tau(440)>=0.80$ & $0.1 \leq \tau 0440) \leq 1.5 ;<\tau(440)>=0.38$ & $0.1 \leq \tau \mathrm{o} 440) \leq 2.0 ;<\tau(440)>=0.40$ \\
\hline Range of Ångstrom exponent & $1.2 \leq \alpha \leq 2.1$ & $1.2 \leq \alpha \leq 2.1$ & $1.4 \leq \alpha \leq 2.2$ & $1.0 \leq \alpha \leq 2.3$ \\
\hline $\mathrm{g}(440 / 670 / 870 / 1020)$ & $0.69 / 0.58 / 0.51 / 0.48 \pm 0.06$ & $0.67 / 0.59 / 0.55 / 0.53 \pm 0.03$ & $0.64 / 0.53 / 0.48 / 0.47 \pm 0.06$ & $0.69 / 0.61 / 0.55 / 0.53 \pm 0.06$ \\
\hline $\mathrm{n} ; \mathrm{k}$ & $1.47 \pm 0.03 ; 0.0093 \pm 0.003$ & $1.52 \pm 0.01 ; 0.015 \pm 0.004$ & $1.51 \pm 0.01 ; 0.021 \pm 0.004$ & $1.50 \pm 0.04 ; 0.0094 \pm 0.003$ \\
\hline$\omega_{0}(440 / 670 / 870 / 1020)$ & $0.94 / 0.93 / 0.91 / 0.90 \pm 0.02$ & $0.91 / 0.89 / 0.87 / 0.85 \pm 0.03$ & $0.88 / 0.84 / 0.80 / 0.78 \pm 0.015$ & $0.94 / 0.935 / 0.92 / 0.91 \pm 0.02$ \\
\hline VMD-fine $(\mu \mathrm{m}) ; \sigma_{g v}$ & $0.28+0.02 \tau(440) \pm 0.02 ; 1.49 \pm 0.06$ & $0.28+0.02 \tau(440) \pm 0.02 ; 1.60 \pm 0.05$ & $0.24+0.05 \tau(440) \pm 0.02 ; 1.49 \pm 0.04$ & $0.30+0.03 \tau(440) \pm 0.02 ; 1.54 \pm 0.04$ \\
\hline VMD-coarse $(\mu \mathrm{m}) ; \sigma_{g v}$ & $6.5+1.2 \tau(440) \pm 0.9 ; 2.2 \pm 0.1$ & $6.5+1.0 \tau(440) \pm 0.8 ; 2.2 \pm 0.1$ & $6.4+1.4 \tau(440) \pm 0.9 ; 2.1 \pm 0.1$ & $6.4+0.4 \tau(440) \pm 0.5 ; 2.2 \pm 0.4$ \\
\hline $\mathrm{C}_{v f}\left(\mu \mathrm{m}^{3} / \mu \mathrm{m}^{2}\right)$ & $0.12 \tau(440) \pm 0.05$ & $0.1 \tau(440) \pm 0.06$ & $0.12 \tau(440) \pm 0.04$ & $0.01+0.1 \tau(440) \pm 0.04$ \\
\hline $\mathrm{C}_{v c}\left(\mu \mathrm{m}^{3} / \mu \mathrm{m}^{2}\right)$ & $0.05 \tau(440) \pm 0.02$ & $0.04+0.03 \tau(440) \pm 0.03$ & $0.09 \tau(440) \pm 0.02$ & $0.01+0.03 \tau(440) \pm 0.03$ \\
\hline
\end{tabular}

The simplest forms of inversion are those based on measurement of spectral optical depth or light extinction. Notable is the application from King et al. (1978) which has also been applied for smoke to lidar backscatter and extinction (e.g., Uthe et al., 1982; Fieberg et al., 2002). Other inversions have included comparisons of optical depth to ground based radiance (e.g., Eck et al., 1998; von Hoyningen-Huene et al., 1999), or between satellite retrievals and ground based optical depth measurements (e.g., early studies such as Kaufman et al., 1990; Ferrare et al., 1990). More recent algorithms have utilized ground based sky radiance information using almucantar and principle plane scans of the sky (e.g., Nakajima et al., 1986; Dubovik and King, 2000).

Taken as a whole, presented inversion data is fairly mixed. At the very least, derived $\omega_{o}$ tend to be consistent. Notably, Nakajima et al. (1999) reported $670 \mathrm{~nm} \omega_{o}$ values of 0.9 for the Indonesian smoke event in 1997. By comparing radiative flux at the surface to optical depth measurements, Eck et al. (1998) and von Hoyningen-Huene (1999) found $\omega_{o}$ on the order of 0.82-0.94 throughout the visible spectrum. Using the approach of Kaufman et al. (1990), Ferrare et al. (1990) retrieved the single scattering albedo of smoke aerosol over forest fire areas in western Canada during summer 1982. Using the AVHRR channels 1 and 2, the single scattering albedo is found to be within the range of 0.9 to 1.0. Similarly, Christopher and Zhang (2002), Knapp et al. (2002), and Wong and $\mathrm{Li}$ (2002) required a $\omega_{o}$ value of $\sim 0.9$ at $670 \mathrm{~nm}$ in order to correctly retrieve optical depth from satellite data (it is noteworthy, however, that such inferences from satellite are based on scattering in the smallest portion of the phase function, scattering angle $100-130^{\circ}$, and are much more uncertain than a full Sun/sky retrieval, Also like the forward problem, there are a number of small perturbations in the physical model that can change these results. See discussion by Wong and $\mathrm{Li}, 2002)$. The lowest values have been presented by Wandinger et al., $2002\left(\omega_{o}=\sim 0.79-0.81\right)$ are based on lidar inversions for a single severe European fire.
Parameters other than $\omega_{o}$ have been far more varied. Early retrievals of smoke gave unphysical size distributions. For example, early publications using Sun photometer inversions of smoke particle size gave volume modal diameters of less than $0.1 \mu \mathrm{m}$ (e.g., Kaufman et al., 1994; Holben et al., 1996a). Smoke size retrievals were then improved by $\mathrm{Re}$ mer et al. (1998) through forcing volume distribution to go to zero at small sizes in the accumulation mode. The resulting volume median diameter $(\sim 0.26 \mu \mathrm{m})$ and equivalent optical effective radius were qualitatively similar (although smaller than fine mode in situ measurements in the region), but coarse mode aerosol particles were significantly overestimated. Also, a lower than is commonly used real part of the refractive index, (1.43), was assumed. Using the same data, Yamasoe et al. (1998) performed sensitivity studies on refractive index and found values ranging from 1.53 at 440 $\mathrm{nm}$ to 1.58 at $1020 \mathrm{~nm}$-somewhat higher than what is typically assumed, and more than 0.10 higher than the assumption of Remer et al. (1998). Using various lidar retrievals, Wandinger et al. (2002) derived values ranging from 1.491.60. But for fires in Malaysia, von Hoyningen-Huene et al. (1999) gave a real part of the refractive index of 1.42. Because of these wide differences in retrieved size and refractive index, the asymmetry parameter, $\mathrm{g}$, also varies considerably, yielding values as high 0.69 (e.g., von HoyningenHuene et al., 1999). Wang and Li (2002) explored the offsetting effects of varying $\omega_{o}$ and $g$ in satellite retrievals as well, and found that fairly large differences in these values that give similar retrieval results.

These types of gross uncertainties have been diminished by the recent use of the Dubovik and King (2000) (henceforth DK) algorithm that utilizes both the spectral optical depth, and sky radiance data in the almucantar to compute retrievals of aerosol size distribution and refractive indices. Using forward modeling techniques, any quantity such as $\alpha_{s}$ (with assumed density), $\omega_{o}$, g or phase function can be computed. The reported uncertainty is due to combined instrumental 
Table 4. Summary of fine mode only biomass burning aerosol optical properties based on retrieved particle size and index of refraction from the Dubovik et al. (2002) climatology from worldwide AERONET network of ground-based radiometers. $\alpha=440-870 \mathrm{~nm}$ Ångstrom exponent, $\alpha_{s}=$ Mass scattering efficiency, $\alpha_{a}=$ Mass absorption efficiency.

\begin{tabular}{lcccc}
\hline & $\begin{array}{c}\text { Amazonian Forest: Brazil (1993-1994); } \\
\text { Bolivia (1998-1999) }\end{array}$ & $\begin{array}{c}\text { South American Cerrado: } \\
\text { Brazil (1993-1995) }\end{array}$ & $\begin{array}{c}\text { African Savanna: } \\
\text { Zambia (1995-2000) }\end{array}$ & $\begin{array}{c}\text { Boreal Forest: USA, } \\
\text { Canada (1994-1998) }\end{array}$ \\
\hline $\begin{array}{l}\text { Fine mode only modeled } \\
\text { (static index of refraction) }\end{array}$ & & & & \\
$\mathrm{g}(440 / 670 / 870 / 1020 \mathrm{~nm})$ & $0.665 / 0.55 / 0.44 / 0.37$ & $0.65 / 0.56 / 0.48 / 0.43$ & $0.66 / 0.54 / 0.44 / 0.76$ & $0.67 / 0.58 / 0.50 / 0.44$ \\
$\omega_{0}(440 / 670 / 870 / 1020 \mathrm{~nm})$ & $0.95 / 0.93 / 0.91 / 0.89$ & $0.925 / 0.91 / 0.885 / 0.86$ & $0.90 / 0.87 / 0.83 / 0.80$ & $0.95 / 0.94 / 0.93 / 0.91$ \\
$\alpha(440$ to $870 \mathrm{~nm})$ & 2.3 & 2.1 & 2.1 & 2.05 \\
$\alpha_{s}(440 / 670 / 870 / 1020 \mathrm{~nm})$ & $5.7 / 2.3 / 1.2 / 0.7$ & $6.2 / 2.8 / 1.5 / 1.0$ & $5.8 / 2.6 / 1.4 / 0.9$ & $6.7 / 3.1 / 1.65 / 1.07$ \\
$\alpha_{s}\left(550 \mathrm{~nm}, \mathrm{~m}^{2} \mathrm{~g}^{-1}\right)$ & $3.5-4.1$ & $4.1-4.7$ & $3.8-4.5$ & $4.5-5.2$ \\
$\alpha_{a}(440 / 670 / 870 / 1020)$ & $0.3 / 0.2 / 0.1 / 0.1$ & $0.5 / 0.3 / 0.2 / 0.2$ & $0.7 / 0.4 / 0.3 / 0.2$ & $0.24-0.28$ \\
$\alpha_{a}\left(550 \mathrm{~nm}, \mathrm{~m}^{2} \mathrm{~g}^{-1}\right)$ & $0.21-0.25$ & $0.36-0.42$ & $0.49-0.57$ & $0.24-0.28$ \\
\hline
\end{tabular}

offsets in measured aerosol optical depth, sky radiance calibration uncertainty, pointing accuracy, and assumed ground reflectance for moderate optical depths (optical depth $>0.5$ ), and has been reported as $\sim 25 \%$ in $d \mathrm{~V} / d \ln \mathrm{d}_{p}$ of the retrieved volume size distributions $\left(0.1 \mu \mathrm{m}<\mathrm{d}_{p}<30 \mu \mathrm{m}\right), \pm 0.04$ for the real part of the refractive index, and $\pm 30 \%$ in the complex index (Dubovik et al., 2000). These sources of uncertainty also result in a reported uncertainty of \pm 0.03 in $\omega_{o}$ and $\sim 0.02$ in $\mathrm{g}$ (Dubovik et al., 2000).

Table 3 summarizes optical inversion retrievals compiled by AERONET scientists for significant burning regions and is an updated version of the climatology presented in Dubovik et al. (2002). Mean particle volume distribution median diameters, standard deviations, and volume concentrations relative to optical depths are presented. Also presented is the Angstrom exponent, mean index of refraction, spectral $\omega_{o}$, and g. To establish if the results are internally consistent, Table 4 presents derived values of these parameters for the biomass burning fine mode if one uses the climatological values for size and index of refraction (it is noteworthy that in particular while

$\omega_{o}$ (total) is insensitive to mixed particles, the derivations the separation of $\omega_{o}$ between fine and coarse mode $\omega_{o}$ can be different if the particles are inhomogeneous). A full evaluation of the AERONET data set is outside the scope of this manuscript. However, as it is the largest and most consistent dataset of its kind, and cited so heavily (over $\sim 200$ citations for retrieval papers) that it is worth some discussion and evaluation.

Direct and simultaneous validation of particle size retrievals for smoke is limited to only one study of one retrieval (Haywood et al., 2003a). But on the whole, particle VMD and $\sigma_{g v}$ derived from DK are reasonably consistent with what has been observed in in situ measurements (see Reid et al., 2004, for a list). The DK inversion does capture trends in particle size by region, correctly yielding larger particle sizes for dense temperate/boreal forest fires.
Recently, Eck et al. (2003b) found, using the DK inversion, that the retrievals of the largest accumulation mode size for smoke in the AERONET network were from highly concentrated plumes of significant age - again consistent with particle growth during the aging process. On a regional basis, comparisons of the fine mode VMD from DK to DMPS values measured in situ from aircraft tracked during the SCARB experiment in Brazil, (Reid et al., 1998b, 1999), showing similar values for both local cerrado smoke (assuming $\tau_{a 440}=1.0$ ) and aged smoke (assuming $\tau_{a 440}=2.0$ ) (Eck et al., 2003a). Retrieved VMD is slightly smaller than data from the differential mobility analyzer (DMPS), which should be less prone to artifact. Conversely, geometric standard deviations from DK match those from differential mobility analyzers, but are considerably larger than those from the PCASP (as discussed earlier, PCASP data underestimates $\sigma_{g v}$ ). Thus, while the absolute values of VMD are within measurements and DK retrieval uncertainties, it is possible that there is a slight but consistent negative bias in mean size $(\sim 0.01-$ $0.02 \mu \mathrm{m}$ ). It is also noteworthy that the retrievals are for ambient size distributions, while the PCASP and DMPS data is for dried aerosol particles. If particle hygroscopicity is as large as suggested by Magi and Hobbs (2003), then an additional 0.02 divergence may exist in VMD, for a total of 0.04 under measurement. Because there is limited validation data, it is unclear whether it is the limited field measurements or the inversions (or both) that are biased. For example, the SCAR-B study occurred during one of the highest burning seasons on record, whereas the DK database has only limited contributions from this place and time period. Regardless, it is likely that trend data from DK shows skill for smoke dominated atmospheres.

If particle size retrievals from inversions such as DK are reasonable, then derived asymmetry parameters should also be within $\sim 0.02$ (e.g., Fig. 2e). Because of the possible negative bias in VMD, these values imply that $\mathrm{g}$ may be underestimated systematically by $\sim 0.01$ or less. But, given that 
AERONET almucantar inversions are "best fits" to sky radiance fields, scattering angles less than $90^{\circ}$ are measured, and there is a very limited amount of in situ data in the literature, the DK values for the asymmetry parameter are probably the most reliable in the field. Entire burning season mean values of mid-visible $(550 \mathrm{~nm}) \mathrm{g}$ range from $\sim 0.59$ for smaller sized African savanna particles to $\sim 0.65$ for the largest boreal/temperate forest smoke particles, (computed from retrievals made at 440 and $675 \mathrm{~nm}$ ). These $g$ values are in general agreement with the suggested value in Sect. 3 of $\sim 0.62$ for aged smoke, based on the limit of 0.10 for the hemispherical backscatter ratio, $\beta(1)$ measured in the field. It is noteworthy however, that this value is substantially lower than the value of 0.69 suggested by von Hoyningen-Huene et al. (1999). This also corresponded to a retrieved index of refraction that was considerably smaller than the values from DK. As this study was for Malaysia, it may be constrained by large haze particles, atypical for isolated biomass smoke. Conversely, this could very well be due to differences between the two inversion algorithms.

While size related parameters appear to be consistent with field measurements, uncertainty (and controversy) comes with the retrieval of particle index of refraction and by implication $\omega_{o}, \alpha_{s}$ and $\alpha_{a}$. This is because even seemingly small variations in these parameters can have large effects. There is no readily available direct methodology to measure aerosol particle index of refraction and, with the exception of a few very rare cases, it is simply inferred by iteration until agreement is found between several measurements (e.g., size and scattering). The DK retrievals of the real part of the refractive index for biomass burning smoke range from an average of 1.47 for Amazonian forest region smoke to 1.52 for South American cerrado smoke. These are in the middle of values commonly used in forward modeling calculations and other retrievals.

Included in Table 3 are the AERONET retrieved values of spectral $\omega_{0}$ for biomass burning particles. It is noteworthy that these values are significantly different from the (unphysical) values in Dubovik et al. (1998) using a modified Nakajima inversion, and have now been superseded by the completely independent DK retrieval method whose results are given in Dubovik et al. (2002). The comparison of the spectral $\omega_{0}$ averages for measurements where $\tau_{a 440}>0.4$ show significant regional differences in the magnitude of $\omega_{0}$, as well as in the slope of the spectral dependence for biomass burning aerosols from different regions. The $\omega_{0}$ values for aged smoke from forested regions (Amazonian tropical forest versus N. American boreal forest) are similar to each other at all wavelengths (within \pm 0.01 ), which is somewhat surprising given the difference in size between the two regions. The $\omega_{0}$ values of the African savanna region, however, are significantly lower than the forested regions and exhibit a steeper rate of decrease in $\omega_{0}$ with increasing wavelength. Values of $\omega_{0}$ for South American cerrado region (made up of grasses, scrub and forest) are intermediate in magnitude, and are the result of smoke from both local and long-range transported plumes. The difference between forested and grassy fuels is consistent with what is known from the scattered in situ measurements. Extensive field measurements in both Brazil and Africa by Ward et al. $(1996,1992)$ have shown that for savanna ecosystems, $\sim 85 \%$ of the biomass (largely grass) was consumed by flaming combustion while for deforestation fires $\sim 50 \%$ or less of the combustion was in the flaming phase. The relatively high values of $\omega_{o}$ measured in forest regions relative to Africa suggests that on the ensemble level, smoldering combustion occurs over a much longer period of time in forests relative to the comparatively short lived flaming phase of the crown fires.

An advantage to inversion methods is that unlike airborne data, long time series can be examined. The AERONET retrievals at some sites exhibit significant trends in $\omega_{0}$ magnitude through the course of the burning season. This added complexity should be accounted for, in addition to the uncertainties given for smoke optical properties listed in Tables 2 and 3. For example, the monthly mean $\omega_{0}$ retrieval at Mongu, Zambia increases from a minimum of $\sim 0.85$ in July (the beginning of the savanna burning season) to $\sim 0.93$ in October at the end of the burning season, or a 0.08 variation (Eck et al., Spring 2002 AGU). The slope of the spectral dependence of aerosol single scattering albedo with wavelength decreased as $\omega_{0}$ increased from July to October. However, there was no significant change in retrieved particle size in either the dominant accumulation or secondary coarse modes during these months. ATSR satellite detected fire counts indicate that the regions of primary biomass burning in southern Africa shifted significantly from July to October (http://shark1.esrin.esa.it/ionia/FIRE/AF/ATSR/). Possible reasons for the seasonal changes in observed $\omega_{0}$ include differences in aging due to transport speed and distance from source regions, differences in biomass fuel types in different regions (fraction of woody biomass versus grasses), and differences in fuel moisture content (October is the beginning of the rainy season).

The difficulty in comparing $\omega_{o}$ from inversions to measurements is the implications to $\alpha_{s}$ and $\alpha_{a}$. Consider as an example derived values from the Amazon Basin. The measured regional $\alpha_{s}$ value for fine mode particles was $4.0 \mathrm{~m}^{2} \mathrm{~g}^{-1}$ for the aged smoke transported out of the Amazon Basin. Average DK inversions however, imply values of 4.2-4.7, depending on whether one assumes a 1.4 or $1.2 \mathrm{~g} \mathrm{~cm}^{-3}$ density. This could be considered good agreement and within experimental error. However, based on a DK derived $\omega_{o}$ value of 0.935 , estimated $\alpha_{a}$ values for this same region are $0.30-0.34 \mathrm{~m}^{2} \mathrm{~g}^{-1}$, or half those than values listed in Reid et al. (1998b) based on $\omega_{o}$ of 0.86. With in situ absorption measurements being argued to overestimate absorption, can the current thinking resolve the two estimates? If we alter the Reid et al. (1998b) findings by adjusting to the optical reflection technique used by Artaxo et al. (1994, 1998) and Martins et al. (1998), which was found to give the 
highest performance on the extinction cell analysis of Reid et al. (1998a), $\omega_{o}$ would increase by 0.02 to 0.88 . Adding additional scattering corrections from Bond et al. (1999) which were not accounted for in the original extinction cell analysis (which was for highly absorbing smoke particles) would add 0.02 , bringing the total $\omega_{o}$ to 0.9 and $\alpha_{a}$ to $0.42 \mathrm{~m}^{2} \mathrm{~g}^{-1}$. Lastly, we consider that the DK inversion is for ambient humidity whereas measurements are for dried aerosol particles. Given that the smoke in the Amazon is in only a moderately humid environment ( $\sim 70 \% \mathrm{RH})$, we apply a maximum hygroscopicity of $\sim 1.3$. This would then give corrected values from Reid et al. (1998b) for $\omega_{o}$ of 0.92 compared to 0.935 from DK. Given that SCAR-B occurred in an anomalously high burning year, it could be argued that there could be seasonal differences.

If for the Amazon region we perform forward calculations based on the climatological values for size and refractive index from DK, assuming a density between 1.2 and $1.4 \mathrm{~g} \mathrm{~cm}^{-3}$ (Table 4), we derive $\alpha_{s}$ and $\alpha_{a}$ of $3.5-4.1 \mathrm{~m}^{2} \mathrm{~g}^{-1}$ and $0.21-0.25 \mathrm{~m}^{2} \mathrm{~g}^{-1}$, respectively. Typically field measurements are higher, roughly 4.0 and $0.4 \mathrm{~m}^{2} \mathrm{~g}^{-1}$ (this is after the $\omega_{o}$ corrections to Reid et al., 1998b, listed above). Hence, even after corrections the implied $\alpha_{a}$ value is still lower than field measurements by a factor of two, and $\alpha_{s}$ is likely underestimated.

Now, consider the South American Cerrado region. In this case the retrieved particle VMD is equivalent to the Amazon case, but retrieved index of refraction is higher at 1.52 $0.0015 \mathrm{i}$, and $\omega_{o}$ is reduced to 0.90 . This now leads to several problems. First, increasing the index of refraction (both real and complex components) without changing the size leads to an increased value of $\alpha_{a}$ and $\alpha_{s}$ to $0.36-0.42$ and 4.1$4.7 \mathrm{~m}^{2} \mathrm{~g}^{-1}$, respectively. These values of $\alpha_{s}$ are now higher than what has been measured in the field, while the values of $\alpha_{a}$ are now equivalent to the corrected field measurements of Reid et al. (1998b) (although still lower than what can be inferred from Artaxo et al., 1994, 1998 and Martins et al., 1998). Typically, high optical depth smoke events in this region are either from smoke transported from the Amazon Basin (extremely well aged) or nearby localized plumes. Local plumes would be more absorbing than their aged smoke, but would also have a much smaller mass scattering efficiency. Aged plumes would have larger sizes, larger $\alpha_{s}$ but smaller $\alpha_{a}$. But here we have increased both $\alpha_{a}$ and $\alpha_{s}$. Now a reduction in $\omega_{o}$ is consistent with the region owing to local production from grass and cerrado fires. But physically, the retrievals of size and index of refraction between the Amazon and Cerrado regions contradict each other. There are two possible reasons for this. First, because the Cerrado region is meteorologically complicated, average climatological values could be biased due to the presence of two distinct sample populations (e.g., aged versus local). This would lead to an "average" value that represents neither-not an uncommon occurrence in climatologies. This can been seen in computed values of $g$ and $\omega_{o}$ in Table 4 , which diverge slightly from their "mean values" (not surprising considering that inversions are not a linear process). Second, while the DK inversion reports fairly low uncertainty in parameters such as $\omega_{o}$ and $\mathrm{g}$, it does have large reported uncertainties in both the volume distribution and the index of refraction. Hence, it is distinctly possible that the DK inversion is prone to degeneracy between the two terms. Another such example is temperate and boreal forest fire smoke, which also shows values of $\omega_{o}(0.94)$ and $\alpha_{s} 4.5-5.2 \mathrm{~m}^{2} \mathrm{~g}^{-1}$, higher than most measured values. In this case however, there is an increase in size, and an intermediate refractive index, which is at least consistent with the physics. But again, derived $\alpha_{a}$ seem considerably low compared to measurements, even after all possible corrections have been accounted for.

Retrievals for Africa, however, appear to be the closest in line with field measurements. Mean values of $\omega_{o}$ are 0.86 , (some of the lowest by region of the world), and are consistent with the high degree of flaming combustion. Particle size for typical optical depths is consistent with the PCASP measurements of Haywood et al. (2003a) for very well aged smoke, and in turn agrees with the PCASP measurements of Reid et al. (1998b) for Brazil. Retrieved index of refraction is average for the four regions as well, and $\alpha_{s}$ is within the upper range of reported values for aged smoke (although $\alpha_{a}$ is slightly lower). Derived and inverted values of $\alpha_{s}, \alpha_{a}$, and $\omega_{o}$ also match, showing there is consistency with the model.

In the conclusion of this section it is clear that while there is some consistency in retrieved $\omega_{o}$ from all inversion methods, results diverge significantly for size and index of refraction. The DK inversion appears to perform better, with trends in particle volume median size and $\omega_{o}$ from retrievals that track with the macroscopic properties of the regions, and have intermediate values of refractive index. This, coupled with the standardization of the AERONET network, makes DK inversions a powerful tool in estimating the variability of smoke optical properties. However, until more detailed validation is performed, this may be as far as the retrievals can be applied without caution. Even after reasonable corrections are made to field measurements, the inferred $\alpha_{a}$ from a calculation of retrieved size and index of refraction still appears low. And while the authors state that their $\omega_{o}$ values are robust, they admit that the volume distribution and real index of refraction values are much more uncertain. Because optical depth "closure" is required in the inversions, one cannot change size without changing index of refraction. Clearly at times the "climatological average" of particle properties are inconsistent with one another (which is not surprising given that the relationship between these parameters is not linear). Because smoke is dynamic in nature one must also be careful about how different sample populations influence average values - which in itself would cause inconsistency in the climatology 
Table 5. Likely optical properties for dry biomass-burning smoke at $550 \mathrm{~nm}$.

\begin{tabular}{|c|c|c|c|c|c|c|c|c|}
\hline Parameter & $\begin{array}{l}\text { IPCC } \\
\text { Fresh }\end{array}$ & $\begin{array}{l}\text { IPCC } \\
\text { Aged }\end{array}$ & $\begin{array}{l}\text { Grass/Savanna } \\
\text { Fresh }\end{array}$ & $\begin{array}{c}\text { Grass/Savanna } \\
\text { Aged }\end{array}$ & $\begin{array}{c}\text { Tropical } \\
\text { Forest Fresh }\end{array}$ & $\begin{array}{c}\text { Tropical } \\
\text { Forest Aged }\end{array}$ & $\begin{array}{l}\text { Temperate/Boreal } \\
\text { Forest Fresh }\end{array}$ & $\begin{array}{l}\text { Temperate/Boreal } \\
\text { Forest Aged }\end{array}$ \\
\hline $\begin{array}{l}\text { Mass Scattering } \\
\text { Efficiency } \alpha_{s}, \mathrm{~m}^{2} \mathrm{~g}^{-1}\end{array}$ & $3.6 \pm 1.0$ & $3.6 \pm 1.1$ & $3.6 \pm 0.4$ & $4.0 \pm 0.4$ & $3.6 \pm 0.4$ & $4.2 \pm 0.4$ & $3.8 \pm 0.4$ & $4.3 \pm 0.4$ \\
\hline $\begin{array}{l}\text { Mass Absorbing } \\
\text { Efficiency } \alpha_{a}, \mathrm{~m}^{2} \mathrm{~g}^{-1}\end{array}$ & $0.54 \pm 0.2$ & $0.45 \pm 0.2$ & $0.80 \pm 0.3$ & $0.65 \pm 0.3$ & $0.6 \pm 0.3$ & $0.50+0.2$ & $0.5 \pm 0.3$ & $0.4 \pm 0.3$ \\
\hline $\begin{array}{l}\text { Single Scattering } \\
\text { Albedo, } \omega_{o}\end{array}$ & $0.87 \pm 0.06$ & $0.89 \pm 0.06$ & $0.821 \pm 0.05$ & $0.86+0.05$ & $0.85 \pm 0.05$ & $89 \pm 0.05$ & $0.88 \pm 0.05$ & $0.915 \pm 0.05$ \\
\hline $\begin{array}{l}\text { Hygroscopic Growth } \\
f(80 \% \mathrm{RH})\end{array}$ & $1.1 \pm 0.1$ & $1.2 \pm 0.2$ & $1.35 \pm 0.2$ & $1.35 \pm 0.2$ & $1.35 \pm 0.2$ & $1.35 \pm 0.2$ & $1.35 \pm 0.2$ & $1.35 \pm 0.2$ \\
\hline $\begin{array}{l}\text { Asymmetry } \\
\text { Parameter, g }\end{array}$ & $0.63+0.12$ & $0.63 \pm 0.16$ & $0.55+0.06$ & $0.58 \pm 0.06$ & $0.59+0.06$ & $0.63 \pm 0.06$ & $0.60 \pm 0.06$ & $0.65 \pm 0.06$ \\
\hline
\end{tabular}

\section{Derivation of likely particle optical properties}

Biomass burning particle's optical properties are perhaps the most variable of any category. Significant differences exist between flaming versus smoldering combustion, wet fuel versus dry, crown fires and under story, fresh versus aged, and between seasons, to name a few. The authors have observed forest fires with extremely dark plumes, $\omega_{0} \sim 0.35$. Conversely, we have witnessed large grass and shrub fires from dry wild lands with substantial flaming combustion emitting what are essentially white plumes. The properties of thick smoke plumes are difficult to measure, and we often find ourselves extrapolating the relatively few field or laboratory measurements to the ensemble of fires of concern to climate scientists. This likely leads to severe sampling and reporting bias. For example, $\omega_{o}$ from the SAFARI2000 campaign for "smoke" listed in Table 2 ranged from 0.83 to 0.93 due to variations in air mass history, mixing with other aerosol species, combustion properties, and perhaps instrumentation error. So what value should be used as representative? The SCAR-B study took place in a year with record high burning activity. To what extent do these measurements reflect the mean? The nature of biomass burning itself makes interpretation of the literature difficult, at the very least. Where do inversions fit in? While the Dubovik and King (2000) inversion is consistently applied globally, other inversion studies place particle properties all over the map.

Contrasting with the variable nature of smoke particles and optical measurements are the wishes of the climate community for simple parameterizations for models and forcing estimates. To this end, a variety of values have been pulled from the literature, from direct measurements, forward models, and more recently from inversions. But since the early 1990 's, there has been more variance in the literature, not less. Not only are there varying techniques now available, but smoke is also measured in more regions, with varying levels of background pollution. If we examine the literature base as a whole, to what extent can all of the differences be reconciled, and what is the true uncertainty in smoke optical properties? As we find that individual measurements and retrievals are deeply at odds with one another, which findings should be treated as "representative?" Because variables such as size, density, index of refraction, $\omega_{o}, \alpha_{s}$ and $\alpha_{a}$ are not "free" parameters, care must be taken such that values are consistent with one another.

We have estimated key parameters to the best of our knowledge, and report them in Table 5. We include the recommendations from the IPCC (2001) as a baseline of discussion for all parameters. We also make recommendations for three broad biomes: grass/savanna, Tropical, and Temperate/Boreal. In all likelihood there exist differences on fine scales, but it is our opinion that the statistics currently support no more than these three categories. We also separate fresh and aged smoke. Because smoke can evolve rapidly, by "fresh" we imply smoke that is $\sim 5$ min old. "Aged smoke" can encompass smoke that is from an hour to several days old. It must be emphasized that all of the estimated parameters should be considered as an average over a large ensemble.

First, consider those variables that have the least uncertainty. Bulk dry mass scattering efficiencies, $\alpha_{s}$, of fresh smoke are solidly measured between $3-4 \mathrm{~m}^{2} \mathrm{~g}^{-1}$, with larger values being associated with larger particles (from either smoldering, or very intense and inefficient combustion). Lower values are typically from grass or cerrado fires, while larger values tend to be from more forested fires. This value increases by $\sim 0.2 \mathrm{~m}^{2} \mathrm{~g}^{-1}$ if one strips out contributions from coarse mode emissions, and a further $\sim 0.3-0.5 \mathrm{~m}^{2} \mathrm{~g}^{-1}$ during the smoke aging process. Despite the fact that there are few in situ measurements of $\alpha_{s}$ for aged smoke in the literature, we do not recommend the use of values derived from inversions due to a possible positive bias (it is noteworthy however, that this is within the noted retrieval uncertainty although it is a consistent bias). Further, while it is reassuring that forward model calculations of those such as Anderson et al. (1996a), Reid and Hobbs (1998), Ross et al. (1998) and Haywood et al. (2003a, b) have reproduced the few field measurements, the large degree of freedom in such calculations makes their weight somewhat less (i.e., this cannot be construed as validation or internal closure). For fresh dry 
smoke at $550 \mathrm{~nm}$, the likely median value estimated by the IPCC of $3.6 \pm 1 \mathrm{~m}^{2} \mathrm{~g}^{-1}$ is probably valid for fine mode only, although the uncertainty in the average of $1.0 \mathrm{~m}^{2} \mathrm{~g}^{-1}$ is probably high. We also recommend a slight increase for fresh temperate/boreal fires due to their increased particle size. Because particle size growth is so well documented at this time (e.g., see Reid et al., 2004), the IPCC assessment of a similar value for aged smoke is likely an underestimate. We recommend dry values on the order of 4.0 to $4.3 \pm 0.5 \mathrm{~m}^{2} \mathrm{~g}^{-1}$ (again, excluding the influence of coarse or giant particles of $\sim 0.03 \mathrm{~m}^{2} \mathrm{~g}^{-1}$ ). Because $\alpha_{s}$ is such a strong constraint on the system, it should be given a very high priority in any future smoke field campaigns. A lack of this fundamental variable in Africa is a serious lapse in the dataset.

Even though it has never been measured directly and presented in the literature, the asymmetry parameter $\mathrm{g}$ is also fairly well constrained. It is supported by a few backscatter ratio measurements in the literature. Because of the sheer frequency of measurements and the fact that they are based on angular radiance data, for the time being g should probably be taken from the Dubovik et al. (2002) climatology listed in Table 3 for aged smoke (knowing that this is consistently lower than some other isolated studies). These values should be considered upper limits for fresh smoke, which, based on the backscatter measurements in Table 2 and estimates in Fig. 2, should be 0.02 to 0.04 lower.

Particle hygroscopicity presents more of a challenge. To date there have been only two published measurements of the hygroscopic growth factor, Kotchenruther and Hobbs (1998) and Magi and Hobbs (2003), from South America and Africa, respectively. Ironically, these two manuscripts use the same instrument but with considerably varying results of 1.1-1.3 and $1.3-1.5$ at $80 \%$ RH for the two respectively. Given the higher concentration of soluble materials such as sulfates and organic acids, one would logically think South America would have the higher values. Also, Magi and Hobbs report hygroscopicity decreasing with age, contrary to the Kotchenruther and Hobbs finding. On the other hand, if this is due to a bias in the measurement, the implications for "closure studies" in Brazil must be called into question, as this would in part close the gap between measurements and inversions (due to very low RH values, this is not as much of an issue in Africa). At the moment, the two measurement sets are irresolvable, and the best that can be done is to split the difference and assume a mean value of 1.35 at $80 \% \mathrm{RH}$, slightly higher than the values of 1.1 and 1.2 suggested by IPCC. Values from inversion studies discussed in the hygroscopicity section support the higher values, but these studies are not tightly constrained. The favorable size comparison between in situ measurements (which are dry) and inversions also makes interpretation more ambiguous. At the very least, the hygroscopicity experiments desperately need to be repeated, and are among the highest priorities of any smoke research. In particular, the effects of hysteresis need to be quantified.
Absorption parameters are the most difficult to assess, and vary more by region. For fresh smoke, measurements of $\omega_{o}$ from extinction cell data are likely fairly certain and make up the largest single dataset (Radke et al., 1988, 1991; Hobbs et al., 1996). Thus they should be given the most weight. Absorption photometer data is of less value for fresh smoke plumes because of long integration times. For mixed phase temperate and boreal fires, median values from absorption photometer techniques are on the order of $0.84 \pm 0.05$ for smoke $\sim 15$ min old. For South America, extinction cell values are lower, with median values for tropical forest and pasture/cerrado on the order of $0.80 \pm 0.05$ and $0.76 \pm 0.07$ respectively. As aircraft values are likely sample biased towards large plumes with extensive flaming combustion, they probably underestimate the impact of mostly pure smoldering combustion having much higher values on the order of 0.96 to 0.98 (e.g., Hobbs et al., 1996). In the case of large regional emissions, median values for $\omega_{o}$ in the mid-visible are probably higher, with values on the order of $0.88-0.92$, $0.83-0.87$, and $0.78-0.85$ for temperate forest, tropical forest, and savanna/cerrado types of ecosystems being more appropriate. This is somewhat lower than what the IPCC (2001) recommends, but we have kept the uncertainty. By inference, $\alpha_{a}$ is likely to be on average $\sim 0.5 \pm 0.20,0.6 \pm 0.20$, $0.85 \pm 0.20 \mathrm{~m}^{2} \mathrm{~g}^{-1}$ for these same ecosystems, respectively.

Next we need to consider filter reflectance based methods such as those from the San Paulo group including Martins et al. $(1996,1998)$ and Yamasoe et al. (2000) which have been shown to match the extinction cells relatively well (Reid et al., 1998a). In this case, it is not $\omega_{o}$ that is fundamentally measured, but rather $\alpha_{a}$. Based on the data from Martins et al. (1998), and making similar adjustments as above, $\alpha_{a}$ values are only $\sim 10 \%$ larger to those above can be derived. Further, the values of Martins et al. were typically $20 \%$ lower than the $\alpha_{a}$ given by Reid et al. (1998b). Given the Martins data is better calibrated, the Reid et al. (1998b) values should be reduced by $20 \%$ The values of Yamasoe et al. (2000) are higher than what we suggest. If we make similar corrections as above and try and compensate for sampling bias values of $\alpha_{a}$, the ensemble of reported values is still higher by $20-40 \%$ than the values suggested by those above. This is mostly due to several highly absorbing plumes that were measured. Part of this difference may also, perhaps, be due to another case of sampling bias. The Yamasoe et al. (2000) measurements were made on the ground very close to fires and before near field evolution process could take place, and hence may underestimate non-absorbing condensed species.

Due to the aging process, a combination of condensation of non-absorbing species and an additional increase in size by coagulation should result in an increase in $\alpha_{s}$ and $\omega_{o}$ and a decrease in $\alpha_{a}$. However, here we reach a branching point on how to weight inversions versus measured quantities. The only "true" measurements of absorption were performed using flux divergence methods on only two occasions in Africa (mid visible $\omega_{o}=0.84-0.88$ Pilewskie et al., 2003; Bergstrom 
et al., 2003) and were close to the AERONET mean. In one side-by-side comparison, $\omega_{o}$ values from an absorption photometer also compared well to a single AERONET retrieval in Africa $\left(\omega_{o}=0.91\right.$; Haywood et al., 2003b). Except for these few cases, there are no other measurements that can be treated with certainty. Because the retrievals of $\alpha_{s}$ in Africa compare well to the host of measurements in the field, and the shift in $\omega_{o}$ between regions is constant with theory, the AERONET inverted values of $\omega_{o}$ and $\alpha_{a}$ are likely to be among the more reliable values for the region. But even here caution is warranted - individual retrievals may still be uncertain. In the case of fires in more forested regions, such as South America, and in some cases from temperate and boreal areas, the high divergence between the $\alpha_{s}$ and $\alpha_{a}$ values measured, and those inferred from inversions, causes more difficulty. In cases of very high retrieved $\alpha_{s}$ (e.g., the Cerrado), retrieved $\alpha_{a}$ values are in line with measurements. For the case of more reasonable $\alpha_{s}$ (say the Amazon forest), $\alpha_{a}$ is lower by a factor of two. But, based on the measurements of Artaxo et al., (1994, 1998) and Echalar et al. (1998), the divergence between the two regions is not nearly so strong (for example ground based measurements over a 4 year period Echalar et al. (1998) found $\alpha_{s}$ values on the order of 1 for the Amazon basin and $1.19 \mathrm{~m}^{2} \mathrm{~g}^{-1}$ for cerrado). Further, the bulk of the high optical depth days in the Cerrado region are from transport of smoke from the Amazon basin (Prins et al., 1998; Remer et al., 1998; Reid et al., 1999). Even if it is argued that the reflectance methods overestimate absorption, at the very least they should be consistent. Based on all of these issues, we recommend a value of $\alpha_{a}$ of $\sim 0.50 \pm 0.15 \mathrm{~m}^{2} \mathrm{~g}^{-1}$ for tropical forested regions. Assuming a fine mode value of $4.2 \mathrm{~m}^{2} \mathrm{~g}^{-1}$ as suggested above, this leads to a dry $\omega_{0}$ of 0.89 for aged dry smoke - identical to IPCC. However because we have altered $\alpha_{s}$, this implies a slightly larger $\alpha_{a}$ than IPCC. Given the hygroscopic growth factors above, for an environment such as Brazil, this would lead to an average $\omega_{o}$ value of 0.91 - consistent with satellite derived values, but still lower than those suggested by AERONET. Using similar logic, for boreal or temperate fires, slightly less absorption is likely and we recommend values of $\alpha_{a}$ of $\sim 0.50 \pm 0.15 \mathrm{~m}^{2} \mathrm{~g}^{-1}$.

One last issue to consider is the selection of appropriate particle indices of refraction. In order for the above optical parameters to agree, they must be unified with the physical model. Here, however, we are more reluctant to give "suggested" values. If we assume average size distributions in the literature from Reid et al. (2004), the index of refraction appears to be $\sim 1.5 \pm 0.015 \mathrm{i}$, and is fairly consistent with the values listed in Table 5. However, because there is such degeneracy between input parameters, we cannot derive anything more specific than this in such a limited amount of space. Also, how this changes as a function of wavelength is fairly uncertain. Our research for a consistent physical and optical model for smoke particles is ongoing.

\section{Conclusions}

In this manuscript, we provide a short review of the optical properties of biomass burning particles. Estimates from in situ measurements, forward calculations, and inversions studies are compared. In the end, we give best estimates for median values of smoke optical properties, knowing full well that each fire has its own character and can deviate significantly from the mean. The main points of the review are summarized below.

- Over the past two decades, measurements of particle mass scattering $\left(\alpha_{s}\right)$ and absorption $\left(\alpha_{a}\right)$ efficiency have been relatively consistent. As these properties are strongly correlated to particle size and black carbon content, their variability is strongly tied to individual fire physics. For example, flaming combustion produces smaller $\alpha_{s}$ and larger $\alpha_{a}$ and $\omega_{o}$ compared to smoldering combustion. Consequently, optical properties of fires change rapidly as they go through their lifecycles.

- Just as aging processes affect smoke particle size and chemistry, they have a significant influence on smoke particle optical properties. Measurements of particle properties made near fires are difficult to apply to large regional smoky-hazes. Coagulation keeps particle black carbon ratios constant, but will resulting an increases $\alpha_{s}$ and $\omega_{o}$ due to the increase in size alone. Condensation or out-gassing processes will increase $\alpha_{s}$ and $\omega_{o}$ and reduce $\alpha_{a}$.

- Smoke particle hygroscopicity is uncertain, with the only two direct measurements in the literature yielding different results. Values derived from inversion methods yield an even larger spread. Almost no data have been presented on particle hysteresis effects.

- We show that there is a wide divergence in forward modeling or "internal closure" calculation methodologies, with differences based in unconstrained assumptions on density, size, black carbon content and index of refraction throughout the literature. While such calculations can be gratifying, ultimately the high degree of freedom in input parameters makes such studies less useful than as typically presented.

- Particle index of refraction is highly uncertain, and is often treated as a free parameter. Differences in the literature can alter the computed $\alpha_{s}, \alpha_{a}$, and $\omega_{o}$ considerably.

- Early inversions studies show very inconsistent results with derived values that were unphysical. Recent inversion studies are better constrained, and show consistency with what is qualitatively known about various biomass-burning regions of the world. However, as in forward modeling, there is a possibility of degeneracy in 
the solutions. This may lead to variability in estimated values of the mass scattering and absorption efficiencies.

- While it has been argued that the bulk of in situ particle measurements overestimate absorption, the bulk of measurements near sources have been made by extinction cell (hence this argument does not hold as well). However, such arguments have merit for regional smoke. Even so, after corrections are made, derived $\alpha_{a}$ values are still considerably higher than what is given by inversions.

- Lastly, we provide estimates of fine mode smoke particle properties. For the most part, these are consistent with what was suggested by IPCC (2001), although we suggest a higher mass scattering efficiency and hygroscopic growth factor.

\section{List of symbols}

\begin{tabular}{ll}
$\alpha$ & Angstrom exponent \\
$\alpha_{a}$ & Mass absorption efficiency \\
$\alpha_{p}$ & Average planetary albedo \\
$\alpha_{s}$ & Mass scattering efficiency \\
$\bar{\beta}$ & Average aerosol backscatter fraction \\
$\beta(1)$ & Hemispheric backscatter ratio \\
$\lambda$ & Wavelength \\
$\sigma_{a}$ & Light absorption coefficient \\
$\sigma_{e}$ & Light extinction coefficient \\
$\sigma_{g c}$ & Geometeric Standard deviation of number \\
& distriubtion (i.e., count) \\
$\sigma_{g v}$ & Geometeric Standard deviation of volume \\
& distriubtion \\
$\sigma_{s}$ & Light scattering coefficient \\
$\tau_{a}$ & Optical depth \\
$\tau_{o}$ & Optical depth at a wavelength of $1 \mu \mathrm{m}$ \\
$\mu$ & Cos $\theta$ \\
$\omega_{o}$ & Single-scattering albedo \\
$\mathrm{A}_{c}$ & Global averaged cloud cover \\
$\mathrm{C}_{v f}$ & Volume concentrations of the fine mode \\
$\mathrm{C}_{v c}$ & Volume concentrations of the coarse mode \\
$f(\mathrm{rh})$ & Relative humidity dependant hygroscopic \\
& growth factor \\
$\mathrm{g}$ & Assymetery paraeter \\
$\mathrm{k}$ & Imaginary part of refractive index \\
$\mathrm{M}_{c p}$ & Average global column integrated aerosol \\
& particle mass loading \\
$\mathrm{n}$ & Real part of refractive index \\
\hline$P$ & Phase function \\
$\mathrm{R}_{s}$ & Average global urface albedo \\
$\mathrm{T}_{a}$ & Average atmospheirc molecular transmission \\
&
\end{tabular}

Acknowledgements. We are grateful the Office of Naval Research Code 322 and the NASA EOS Interdisciplinary Science Program
(EOS/IDS) for supporting this work. Additional assistance was provided by the German American Academic Council (GAAC). We are most grateful to Tami Bond and Dean Hegg of the University of Washington for their helpful comments as well as those of an anonymous reviewer.

Edited by: A. Petzold

\section{References}

Abel, S., Haywood, J. M., Highwood, E. J., Li, J., and Buseck, P. R.: Evolution of biomass burning aerosol properties from an agricultural fire in south Africa, Geophys. Res. Lett., 30, 15, 1783, doi:10.1029/2003GL017342, 2003.

Anderson, B. E., Grant, W. B., Gregory, G. L., Browell, E. V., Collins Jr., J. E., Sachse, D. W, Bagwell, D. R., Hudgins, C. H., Blake, D. R., and Blake, N. J.: Aerosols from biomass burning over the tropical South Atlantic region: Distributions and impacts, J. Geophys. Res., 101, 24 117-24 137, 1996a.

Anderson, T. L., Covert, D. S., Marshal, S. F., Laucks, M. L., Charlson, R. J., Waggoner, A. P., Ogren, J. A., Caldow, R., Holm, R., Quant, F., Sem, G., Wiedensohler, A., Ahlquist, N. A., and Bates, T. S.: Performance characteristics of a high-sensitivity, three-wavelength, total scatter/backscatter nephelometer, J. Atmos. Oceanic Tech., 13, 967-986, 1996b.

Ångstrom, A.: On the atmospheric transmission of sun radiation and on dust in the air, Geogr. Ann., 12, 130-159, 1929.

Artaxo, P., Fernandes, E. T., Martins, J. V., Yamasoe, M. A., Hobbs, P. V., Maenhaut, W., Longo, K. M., and Castanho, A.: Largescale aerosol source apportionment in Amazonia, J. Geophys. Res., 103, 31 837-31 847, 1998.

Artaxo, P., Gerab, F., Yamasoe, M. A., and Martins, J. V.: Fine mode aerosol composition at three long term atmospheric monitoring sites in the Amazon Basin, J. Geophys. Res., 99, 22857 $22868,1994$.

Bergstrom, R. W., Pilewskie, P., Schmidt, B., and Russell, P. B.: Estimates of the single scattering albedo and aerosol radiative effects during SAFARI 2000, J. Geophys. Res., 108, doi:10.1029/2002JD002435, 2003.

Bond, T. C., Anderson, T. L., and Campbell, D.: Calibration and intercomparison of filter-based measurements of visible light absorption by aerosols, Aero. Sci. Technol., 30, 582-600, 1999.

Campbell, D., Copeland, S., and Cahill, T. A.: Response to "Comment on 'Measurement of aerosol absorption coefficient from Teflon filters using the integrating plate and integrating sphere techniques", Aerosol Sci. Technol., 24, 225-229, 1996.

Chang, H. and Charalampopoulos, T. T.: Determination of the wavelength dependence of refractive indices of flame soot, Proc. R. Soc. London, Ser. A, 430, 577-591, 1990.

Charlson, R. J., Langer, J., Rodhe, H., Leovy, C. B., and Warren, S. G.: Perturbation of the northern hemisphere radiative balance by backscattering from anthropogenic sulfate aerosols, Tellus, 43A, 152-163, 1991.

Christopher, S. A. and Zhang, J.: Daytime variation of shortwave direct radiative forcing of biomass burning aerosols from GOES 8 imager, J. Atmos. Sci., 59, 681-691, 2002.

Chylek, P. and Wong, J.: Effects of absorbing aerosols on the global radiative balance, Geophys. Res. Lett., 22, 929-931, 1995. 
Clarke, A. D., Noone, K. J., Heintzenberg, J., Warren, S. G., and Covert, D. S.: Aerosol light absorption measurement techniques: Analysis and intercomparisons, Atmos. Environ., 21, 1455-1465, 1987.

Colbeck, I., Atkinson, B., and Johar, Y.: The morphology and optical properties of soot produced by different fuels, J. Aerosol Sci., 28, 715-723, 1997.

Dubovik, O. and King, M. D.: A flexible inversion algorithm for retrieval of aerosol optical properties from Sun and sky radiance measurements, J. Geophys. Res., 105, 20 673-20 696, 2000.

Dubovik, O., Smirnov, A., Holben, B. N., King, M. D., Kaufman, Y. J., Eck, T. F., and Slutsker, I.: Accuracy assessment of aerosol optical properties retrieval from AERONET sun and sky radiance measurements, J. Geophys. Res., 105, 9791-9806, 2000.

Dubovik, O., Holben, B. N., Eck, T. F., Smirnov, A., Kaufman, Y. J., King, M. D., Tanre, D., and Slutsker, I.: Variability of absorption and optical properties of key aerosol types observed in worldwide locations, J. Atmos. Sci., 59, 590-608, 2002.

Echalar, F., Artaxo, P., Martins, J. V., Yamasoe, M., Gerab, F., Maenhaut, W., and Holben, B.: Long-term monitoring of atmospheric aerosols in the Amazon Basin: Source identification and apportionment, J. Geophys. Res, 103, 31 849-31 864, 1998.

Eck, T. F., Holben, B. N., Reid, J. S., O’Neill, N. T., Schafer, J. S., Dubovik, O., Smirnov, A., Yamasoe, M. A., and Artaxo, P.: High aerosol optical depth biomass burning events: a comparison of optical properties for different source regions, Geophys. Res. Lett., 30, 2035, doi:10.1029/2003GL017861, 2003 a.

Eck, T. F., Holben, B. N., Ward, D. E., Mukelabai, M. M., Dubovik, O., Smirnov, A., Schafer, J. S., Hsu, N. C., Piketh, S. J., Queface, A., Le Roux, J., and Slutsker, I.: Variability of biomass burning aerosol optical characteristics in southern Africa during the SAFARI 2000 dry season campaign and a comparison of single scattering albedo estimates from radiometric measurements, J. Geophys. Res., 108(D13), 8477, doi:10.1029/2002JD002321, 2003b.

Eck, T. F., Holben, B. N., Ward, D. E., Dubovik, O., Reid, J. S., Smirnov, A., Mukelabai, M. M., Hsu, N. C., O’Neill, N. T., and Slutsker, I.: Characterization of the optical properties of biomass burning aerosols in Zambia during the 1997 ZIBBEE field campaign, J. Geophys. Res., 106, 3425-3448, 2001.

Eck, T. F., Holben, B. N., Reid, J. S., Dubovik, O., Smirnov, A., O’Neill, N. T., Slutsker, I., and Kinne, S.: Wavelength dependence of the optical depth of biomass burning, urban and desert dust aerosols, J. Geophys. Res., 104, 31 333-31 349, 1999.

Eck, T. F., Holben, B. N., Slutsker, I., and Setzer, A.: Measurements of irradiance attenuation and estimation of aerosol single scattering albedo for biomass burning aerosols in Amazonia, J. Geophys. Res., 103, 31 865-31 878, 1998.

Fieberg, M., Petzold, A., Wandinger, U., Wendisch, M., Kiemle, C., Stifter, A., Ebert, M., Rother, T., and Leiterer, U.: Optical closure for an aerosol column: Method, accuracy, and inferable properties applied to a biomass-burning aerosol and its radiative forcing, J. Geophys. Res., 107(D21), art.-no. 8130, 2002.

Formenti, P., Elbert, W., Maenhaut, W., Haywood, J., Osborne, S., and Andreae, M. O.: Inorganic and carbonaceous aerosols during the Southern African Regional Science Initiative (SAFARI 2000) experiment: Chemical characteristics, physical properties, and emission data for smoke from African biomass burning, J. Geophys. Res., 108(D13), 8488, doi:10.1029/2002JD002408, 2003.
Formenti, P., Reiner, T., Sprung, D., Andreae, M. O., Wendisch, M., Wex, H., Kindred, D., Dewey, K., Kent, J., Tzortziou, M., Vasaras, A., and Zerefos, C.: STAAARTE-MED 1998 summer airborne measurements over the Aegean Sea: 2. Aerosol scattering and absorption, and radiative calculations, J. Geophys. Res., 107, doi:10.1029/2001JD001536, 2002.

Gras, J. L., Jensen, J. B., Okada, K., Ikegami, M., Zaizen, Y., and Makino, Y.: Some optical properties of smoke aerosol in Indonesia and tropical Australia, Geophys. Res. Lett., 26, 1393-1396, 1999.

Guyon, P., Graham, B., Beck, J., Boucher, O., Gerasopoulos, E., Mayol-Bracero, O. L., Roberts, G. C., Artaxo, P., and Andreae, M. O.: Physical properties and concentration of aerosol particles over the Amazon tropical forest during background and biomass burning conditions, Atmos. Chem. Phys., 3, 951-967, 2003,

SRef-ID: 1680-7324/acp/2003-3-951.

Haywood, J., Francis, P., Dubovik, O., Glew, M., and Holben, B.: Comparison of aerosol size distributions, radiative properties, and optical depths determined by aircraft observations and Sun photometers during SAFARI 2000, J. Geophys. Res., 108, doi:10.1029/2002JD002250, 2003a.

Haywood, J. M., Osborne, S. R., Francis, P. N., Keil, A., Formenti, P., Andreae, M. O., and Kaye, P. H.: The mean physical and optical properties of regional haze dominated by biomass burning aerosol measured from the C-130 aircraft during SAFARI 2000, J. Geophys. Res., 108, doi:10.1029/2002JD002226, 2003b.

Heintzenberg, J., Charlson, R. J., Clarke, A. D., Liousse, C., Ramaswamy, V., Shine, K. P., and Wendisch, M.: Measurements and modeling of aerosol single-scattering albedo: Progress, problems and prospects, Beitr. Phys. Atmos., 70, 249-263, 1997.

Hobbs, P. V., Reid, J. S., Herring, J. A., Nance, J. D., Weiss, R. E., Ross, J. L., Hegg, D. A., Ottmar, R. D., and Liousse, C.: Particle and trace-gas measurements in smoke from prescribed burns of forest products in the Pacific Northwest, in: Biomass Burning and Global Change, Vol. 1, edited by: Levine, J. S., MIT Press, New York, 697-715, 1996.

Hobbs, P. V. and Radke, L. F.: Cloud condensation nuclei from a simulated forest fire, Science, 163, 279-280, 1969.

Hobbs, P. V., Reid, J. S., Kotchenruther, R. A., Ferek, R. J., and Weiss, R.: Direct radiative forcing by smoke from biomass burning, Science, 275, 1776-1778, 1997.

Holben, B. N., Eck, T. F., Setzer, A., et al.: Temporal and spatial variability of aerosol loading and properties during the Amazon, North American temperate, and boreal forest burning seasons, Biomass Burning and Global Change, Vol. 2, edited by: Levine, J. S., MIT Press, New York, 618-636, 1996a.

Holben, B. N., Setzer, A., Eck, T. F., Pereira, A., and Slutsker, I.: Effect of dry-season biomass burning on Amazon basin aerosol concentrations and optical properties, 1992-1994, J. Geophys. Res., 101, 19465-19481, 1996b.

Horvath, H.: Atmospheric light absorption-a review, Atmos. Environ., 27A, 293-317, 1993.

Intergovernmental Panel on Climate Change (IPCC): Climate Change 2001: Radiative Forcing of Climate Change, edited by: Houghton, J. T., Ding, Y., Griggs, D. J., Noguer, M., van der Linden, P. J., and Xiaosu, D., Cambridge Univ. Press, Cambridge, 2001.

Iziomon, M. G. and Lohman, U.: Optical and meteorological properties of smoke-dominated haze at the ARM Southern 
Great Plains Central Facility, Geophys. Res. Lett., 30(3), 1123, doi:10.1029/2002GL016606, 2003.

Janzen, J.: Extinction of light by highly non-spherical strongly absorbing particles: Spectrophotometric determination of volume distribution for carbon blacks, Appl. Opt., 19, 2977-2985, 1980.

Kasten F.: Visibility in the phase of pre-condensation, Tellus, 21, 631-635, 1969.

Kaufman, Y. J.: Satellite sensing of aerosol absorption, J. Geophys. Res., 92, 4307-4317, 1987.

Kaufman, Y. J., Fraser, R. S., and Ferrare, R. A.: Satellite measurements of large-scale air pollution, J. Geophys. Res., 95, 98959909, 1990.

Kaufman Y. J., Gitelson, A., Karnieli, A., Ganor, E., Frasier, R. S., Mattoo, S., and Holben, B. N.: Size distribution and scattering phase function of aerosol particles retrieved from sky brightness measurements, J. Geophys. Res., 99, 10 341-10356, 1994.

King, M. D., Byrne, D. M., Herman, J. M., and Reagan, J. A.: Aerosol Size distributions obtained by inversion of spectral optical depth measurements, J. Atmos. Sci., 35, 2153-2167, 1978.

Kinne, S.: Monthly averages of aerosol properties: comparing regionally, monthly averages: among models and to data, Fall Meeting of the Am. Geophys. Union, San Francisco, Dec. 10$15,2002$.

Knapp, K. R., Vonder Haar, T. H., and Kaufman, Y. J.: Aerosol optical depth retrieval from GOES-8: Uncertainty study and retrieval validation over South America, J. Geophys. Res., 107, doi:10.1029/2001JD000505, 2002.

Kotchenruther, R. and Hobbs, P. V.: Humidification factors of aerosols from biomass burning in Brazil, J. Geophys. Res., 103, 32 081-32 090, 1998.

Kreidenweis, S. M., Remer, L. A., Bruintjes, R., and Dubovik, O.: Smoke aerosol from biomass burning in Mexico: Hygroscopic smoke model, J. Geophys. Res., 106, 4831-4844, 2001.

$\mathrm{Ku}$, J. C. and Shim, K. H.: A comparison of solutions for lightscattering and absorption by agglomerated or arbitrary shaped particles, J. Quant. Spectro. Radiative Transfer, 47, 201-220, 1992.

Langmann, B. and Graff, H.: Indonesian smoke aerosols from peat fires and the contribution from volcanic sulfur emissions, Geophys. Res. Lett., 30(11), art.-no. 1547, 2003.

Liousse, C., Devaux, C., Dulac, F., and Cachier, H.: Aging of savannah biomass burning aerosols: Consequences on their optical properties, J. Atmos. Chem., 22, 1-17, 1995.

Magi, B. I., Hobbs, P. V., Schmid, B., and Redemann, J.: Vertical profile of light scattering, 46 light absorption, and singlescattering albedo during the dry, biomass burning season in southern Africa and comparisons of in situ and remote sensing measurements of aerosoloptical depth, J. Geophys. Res., 108(D13), 8504, doi:10.1029/2002JD002361, 2003.

Martins, J. V., Artaxo, P., Hobbs, P. V., Liousse, C., Cachier, H., Kaufman, Y., and Plana-Fattori, A.: Particle size distributions, elemental compositions, carbon measurements, and optical properties of smoke from biomass burning in the Pacific Northwest of the United States, in: Global Biomass Burning and Global Change, edited by: Levine, J. S., MIT Press, Cambridge, Mass, 716-732, 1996.

Martins, J. V., Artaxo, P., Liousse, C., Reid, J. S., Hobbs, P. V., and Kaufman, Y. J.: Effects of black carbon content, particle size, and mixing on light absorption by aerosols from biomass burning in
Brazil, J. Geophys. Res., 103, 32 041-32 050, 1998 a.

Martins, J. V., Hobbs, P. V., Weiss, R. E., and Artaxo, P.: Sphericity and morphology of smoke particles from biomass burning in Brazil, J. Geophys. Res., 103, 32 051-32 058, 1998 b.

Miller, J. R. and O'Neill, N. T.: Multi-altitude airborne observations of isolation effects of forest fire smoke aerosols at BOREAS: Estimates of aerosol optical parameters, J. Geophys. Res., 102, 29729-29736, 1997.

Mulholland, G. W., McKenzie, R. L., Marx, E., and Fletcher, R. A.: Refractive index and evaporation rate of individual smoke droplets, Langmuir, 1, 367-372, 1985.

Nakajima, T., Takamura, T., Yamano, M., Shiobara, M., Yamauchi, T., Goto, R., and Murai, K.: Consistency of aerosol size distributions inferred from measurements of solar radiation and aerosols, J. Meteor. Soc. Japan, 64, 765-776, 1996.

Nakajima T., Higurashi, A., Takeuchi, N., and Herman, J. R.: Satellite and ground-based study of optical properties of 1997 Indonesian forest fire aerosols, Geophys. Res. Lett., 26, 2421-2424, 1999.

Nance, J. D., Hobbs, P. V., Radke, L. F., and Ward, D. E.: Airborne measurements of gases and particles from an Alaskan wildfire, J. Geophys. Res., 98, 14 873-14 882, 1993.

O’Neill, N. T., Eck, T. F., Holben, B. N., Smirnov, A., Royer, A., and Li, Z.: Optical properties of boreal forest fire smoke derived from Sun photometry, J. Geophys. Res., 107, doi:10.1029/2001JD000877, 2002.

Orr, C., Hurd, F. K., and Corbett, W. J.: Aerosol size and relative humidity, J. Colloid Sci., 13, 472-482, 1959.

Patterson, E. M. and McMahon, C. K.: Absorption characteristics of forest fire particulate matter, Atmos. Environ., 18, 2541-2551, 1984.

Patterson, E. M., McMahon, C. K., and Ward, D. E.: Absorption properties and Graphitic carbon emission factors of forest fire smoke, Geophys. Res. Lett., 13, 129-132, 1986.

Penner, J. E., Dickinson, R., and O'Neil, C.: Effects of aerosol from biomass burning on the global radiation budget, Science, 256, 1432-1434, 1992.

Pilewskie, P., Pommier, J., Bergstrom, R., Gore, W., Rabbette, M., Howard, S., Schmid, B., and Hobbs, P. V.: Solar Spectral Radiative Forcing During the South African Regional Science Initiative, J. Geophys. Res., 108, doi:10.1029/2002JD002411, 2003.

Prins, E. M. and Menzel, W. P.: Trends in South American biomass burning detected with the GOES visible infrared spin scan radiometer atmospheric sounder from 1983 to 1991, J. Geophys. Res., 99, 16 719-16735, 1994.

Radke, L. F., Hegg, D. A., Hobbs, P. V., Nance, J. D., Lyons, J. H., Larsen, K. K., Weiss, R. E., Regan, P. J., and Ward, D. E.: Particulate and trace emissions from large biomass fires in North America, in: Global Biomass Burning: Atmospheric, Climatic, and Biospheric Implications, edited by: Levine, J. S., MIT Press, Cambridge, MA, 209-224, 1991.

Radke, L. F., Hegg, D. A., Hobbs, P. V., and Penner, J. E.: Effects of aging on the smoke from a large forest fire, Atmos. Res., 38, 315-332, 1995.

Radke, L. F, Hegg, D. A., Lyons, J. H., Brock, C. A., Hobbs, P. V., Weiss, R., and Rassmussen, R.: Airborne measurements on smokes from biomass burning, in: Aerosols and Climate, edited by: Hobbs, P. V. and McCormick, M. P., Deepak Publishing, Hampton VA, 411-422, 1988. 
Redemann, J., Russell, P. B., and Hamill, P.: Dependence of aerosol light absorption and single-scattering albedo on ambient relative humidity for sulfate aerosols with black carbon cores, J. Geophys. Res., 106, 27 485-27 495, 2001.

Reid, J. S. and Hobbs, P. V.: Physical and optical properties of smoke from individual biomass fires in Brazil, J. Geophys. Res., 103, 32 013-32 031, 1998.

Reid, J. S., Hobbs, P. V., Liousse, C., Martins, J. V., Weiss, R. E., and Eck, T. F.: Comparisons of techniques for measuring shortwave absorption and black carbon content of aerosols from biomass burning in Brazil, J. Geophys. Res., 103, 32 031-32 040, 1998a.

Reid, J. S., Hobbs, P. V., Ferek, R. J., Blake, D. R., Martins, J. V., Dunlap, M. R., and Liousse, C.: Physical, chemical and optical properties of regional hazes dominated by smoke in Brazil, J. Geophys. Res., 103, 32 059-32 080, 1998b.

Reid, J. S., Eck, T. F., Christopher, S. A., Hobbs, P. V., and Holben, B. N.: Use of the Angstrom exponent to estimate the variability of optical and physical properties of aging smoke particles in Brazil, J. Geophys. Res., 104, 27 489-27 489, 1999.

Remer, L. A., Kaufman, Y. J., Holben, B. N., Thompson, A. M., and McNamara, D.: Biomass burning aerosol size distribution and modeled optical properties, J. Geophys. Res., 103, 31879 $31891,1998$.

Ross, J., Hobbs, P. V., and Holben, B.: Radiative characteristics of regional haze dominated by smoke from biomass burning in Brazil: Closure tests and direct radiative forcing, J. Geophys. Res., 103, 31 925-31 942, 1998.

Russell, P. B., Redemann, J., Schmid, B., et al.: Comparison of aerosol single-scattering albedos derived by diverse techniques in two North Atlantic experiments, J. Atmos Sci., 59,609-619, 2002.

Shettle, E. P. and Fenn, R. W.: Models for the Aerosols of the Lower Atmosphere and the Effects of Humidity Variations on Their Optical Properties, AFGL-TR-79-0214, 94, 1979.

Sorensen, C. M.: Light scattering by fractal aggregates: A review, Aerosol Sci. Technol., 35, 649-687, 2001.

Sutherland, R. A. and Khanna, R. K.: Optical properties of organicbased aerosols produced by burning vegetation, Aerosol Sci. Technol., 14, 331-342, 1991.
Tomasi, C., Caroli, E., and Titale, V.: Study of the relationship between Ångstrom's wavelength exponent and Junge particle size distribution exponent, J. Climate Appl. Meteor., 22, 1707-1716, 1983.

Twomey, S.: Application of numerical filtering to solution of integral equations encountered in indirect sensing measurements, J. Franklin Institute, Eng. And Math., 279, 95-100, 1965,

Uthe, E. E., Morely, B. M., and Nielsen, N. B.: Airborne lidar measurements of smoke plume distribution, vertical transmission, and particle size, Appl. Opt., 21, 460-463, 1982.

von Hoyningen-Huene, W., Schmidt, T., Schienbein, S., Kee, C. A., and Tick, L. J.: Climate relevant aerosol parameters of SouthEast-Asian forest fire haze, Atmos. Environ., 33, 3183-3190, 1999.

Waggoner, A. P., Weiss, R. E., and Ahlquis, N. C.: Optical characteristics of atmospheric aerosols, Atmos. Environ., 15, 18911909, 1981.

Wandinger, U., Muller, D., Bockmann, C., Althausen, D., Matthias, V., Bosenberg, J., Weiss, V., Fieberg, M., Wendisch, M., Stohl, A., and Ansmann, A.: Optical and microphysical characterization of biomass burning and industrial pollution aerosols from multi-wavelength lidar and aircraft measurements, J. Geophys. Res., 107, doi:10.1029/2000JD000202, 2002.

Ward, D. E., Hao, W. M., Susott, R. A., Babbitt, R. E., Shea, R. W., Kauffman, J. B., and Justice, C. O.: Effect of fuel composition on combustion efficiency and emission factors for African savanna ecosystems, J. Geophys. Res., 101, 23 569-23 576, 1996.

Ward, D. E., Susott, R. A., Kaufman, J. B., Babbit, R. E., Cummings, D. L., Dias, B., Holben, B. N., Kaufman, Y. J., Rasmussen, R. A., and Setzer, A. W.: Smoke and fire characteristics for cerrado and deforestation burns in Brazil: Base-B Experiment, J. Geophys. Res., 97, 14 601-14 619, 1992.

Wong, J. and Li, Z.: Retrieval of optical depth for heavy smoke aerosol plumes: uncertainties and sensitivities to the optical properties, J. Atmos. Sci., 59, 250-261, 2002.

Yamasoe, M. A., Artaxo, P., Miguel, A. H., and Allen, A. G.: Chemical composition of aerosol particles from direct emissions of vegetation fires in the Amazon Basin: water-soluble species and trace elements, Atmos. Environ., 34, 1641-1653, 2000. 